\title{
Sea surface temperature as a proxy for convective gravity wave excitation: a study based on global gravity wave observations in the middle atmosphere
}

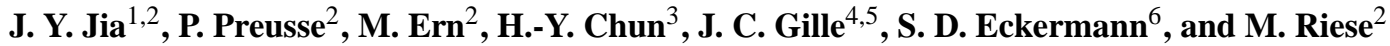 \\ ${ }^{1}$ Key Laboratory of Meteorological Disaster of Ministry of Education, Nanjing University of Information Science \& \\ Technology, Nanjing, China \\ ${ }^{2}$ Institut für Energie- und Klimaforschung - Stratosphäre, Forschungszentrum Jülich GmbH, Jülich, Germany \\ ${ }^{3}$ Department of Atmospheric Sciences, Yonsei University, Seoul, South Korea \\ ${ }^{4}$ Center for Limb Atmospheric Sounding, University of Colorado at Boulder, Boulder, Colorado, USA \\ ${ }^{5}$ National Center for Atmospheric Research, Boulder, Colorado, USA \\ ${ }^{6}$ Space Science Division, Naval Research Laboratory, Washington DC 20375, USA
}

Correspondence to: J. Y. Jia (jiajianying@escience.cn)

Received: 29 January 2014 - Revised: 16 September 2014 - Accepted: 21 September 2014 - Published: 5 November 2014

\begin{abstract}
Absolute values of gravity wave momentum flux (GWMF) deduced from satellite measurements by the Sounding of the Atmosphere using Broadband Emission Radiometry (SABER) instrument and the High Resolution Dynamics Limb Sounder (HIRDLS) are correlated with sea surface temperature (SST) with the aim of identifying those oceanic regions for which convection is a major source of gravity waves (GWs). Our study identifies those latitude bands where high correlation coefficients indicate convective excitation with confidence. This is based on a global ray-tracing simulation, which is used to delineate the source and wind-filtering effects. Convective GWs are identified at the eastern coasts of the continents and over the warm water regions formed by the warm ocean currents, in particular the Gulf Stream and the Kuroshio. Potential contributions of tropical cyclones to the excitation of the GWs are discussed. Convective excitation can be identified well into the midmesosphere. In propagating upward, the centers of GWMF formed by convection shift poleward. Some indications of the main forcing regions are even shown for the upper mesosphere/lower thermosphere (MLT).
\end{abstract}

Keywords. Meteorology and atmospheric dynamics (middle atmosphere dynamics)

\section{Introduction}

Understanding the coupling mechanisms between the different layers forming the atmosphere is essential for understanding the earth's climate. Atmospheric gravity waves (GWs) are one important coupling mechanism because they transport a great portion of momentum from the lower to the higher altitudes and contribute to the formation of the global circulation.

They are, however, not well represented in general circulation models (GCMs). Therefore, excitation, propagation and dissipation of GWs have received increasing attention (Kim et al., 2003; Alexander et al., 2010). In particular, many studies such as the recent global survey of Geller et al. (2013) highlight the need for better source specification for GWs from sources other than orography in order to improve GW parameterizations in GCMs.

In general, the distribution of GWs at a specific altitude is given by GW sources and the propagation condition between the source and the targeted altitude. The most important sources include topography, convection, wind shear and spontaneous adjustment of flow in geostrophic imbalance (Eckermann and Preusse, 1999; Fritts and Alexander, 2003; Wu and Eckermann, 2008; Kirkwood et al., 2010). Sources such as convection or spontaneous adjustment depend on meteorological conditions. However, conventional non-orographic GW parameterizations used in almost all 
GCMs are based on a fixed source distribution constant in time and space. Such tuned non-orographic GW schemes cannot capture the full feedback of GWs in a changing climate. Efforts are therefore made to understand the physical GW sources and to implement them in GCMs (e.g., Richter et al., 2010).

Ground-based and in situ observations (e.g., Pfister et al., 1993; Alexander and Pfister, 1995; Alexander et al., 2000; R'echou et al., 2013) as well as global climatologies from satellite observations (e.g., McLandress et al., 2000; Preusse et al., 2001a; Jiang et al., 2004b) have identified convection as a prominent source of GWs. Gravity waves generated by deep convection are frequently located in the tropics and subtropics, which are characterized by warm sea surface temperature (SST) and more latent heating, which is a favorable condition for deep convection (e.g., Sud et al., 1999; Zhang, 1993). Preusse and Ern (2005) correlated SST and GW variances from Cryogenic Limb Array Etalon Spectrometer (CLAES) temperature data. They found that there is strong convective excitation over the Gulf of Mexico and the Kuroshio Current for the Northern Hemisphere summer. These two regions are primary pathways for hurricanes and typhoons, respectively, and convection associated with hurricanes/typhoons can be a significant source of positive gravity wave momentum flux (GWMF) that is required to maintain large-scale circulation in the summer mesosphere (Kim et al., 2005; Kim and Chun, 2010). In addition, in the southern subtropics, regions of presumably convective GW excitation during the respective summer months were identified as well. Wright and Gille (2011) investigated the correlation between GWMF from the High Resolution Dynamics Limb Sounder (HIRDLS) and outgoing long-wave radiation (OLR) and precipitation which denotes the density of the convection over the monsoon regions. Their study indicated that there is an increase in measured momentum flux of approximately $50 \%$ over the $10-30^{\circ} \mathrm{N}$ latitude band during the boreal monsoon period.

Convection is going to change in a changing climate. Explicitly including this source in climate models therefore could enhance the fidelity of climate forecasts. However, larger differences are found in particular for the location of GWMF patterns from convection: various models (Richter et al., 2010; Geller et al., 2011) have their largest momentum flux of tropical gravity waves over the intertropical convergence zone (ITCZ) region, whereas observations indicate that the largest low-latitude fluxes are over the summer tropical continent regions. In addition, there are different models for the excitation of GWs due to convection (e.g., Beres et al., 2005; Song et al., 2007). Furthermore, these models use freely tunable parameters and are based on various assumptions. Therefore, validation is required. As a first step, it is important to identify those regions where convection is an important GW source solely by observations.

There are now several approaches to identify convectively generated GWs. For instance, McLandress et al. (2000),
Preusse et al. (2001a), and Jiang et al. (2004b) consider spatial collocations of GWs with cloud observations. The second way is to employ a parameterization scheme for convective GW excitation and to compare the modeled GW variances or momentum fluxes with the measurements (e.g., Choi et al., 2009, 2012). However, the convective GW schemes are based on a simplified physical model and assume parameters such as the dominant timescale. Therefore, simpler approaches to identify regions of convectively forced GWs could complement more sophisticated methods since such approaches are less biased by physical expectations. For instance, a complementary method is to analyze correlations between suitable proxies for convection and measured GW distributions (Preusse and Ern, 2005; Wright and Gille, 2011) in order to identify regions where convection is the dominant source.

In this paper we follow the correlation approach. Our aim is to identify those regions where a significant part of the observed GWMF stems from convective sources. We consider distributions of GWMF since it is GWMF that determines the coupling among the different layers of the atmosphere. We choose SST as a proxy for precipitation for several reasons:

1. We base our study on the hypothesis of a causal relation between SST and convective GW excitation. Deep convection usually occurs during a "convectively active season". Over the ocean this convectively active season is facilitated by enhanced SST. In addition, deep convection is a far more effective source of GWs than shallow convection. Therefore, our working hypothesis implies that the time of maximum SST marks the convectively active season and is accordingly the time of enhanced convective GW excitation.

2. SST is a relatively weakly structured proxy. This is of advantage for two reasons. First, GWs propagate obliquely (e.g., Sato et al., 2003; Jiang et al., 2004b; Kalisch et al., 2014) and spread from their sources. The region of enhanced GWMF is therefore larger than the source region itself. With a weakly structured proxy we can capture the entire region of enhanced GWMF. In contrast, a highly structured proxy would identify only those convectively excited GWs which propagate almost vertically and remain in the source region. Second, as will be described in detail below, we isolate convectively excited GWs by identifying local patterns. If the proxy is weakly structured, local patterns in the correlations raise confidence that the identified patterns are indeed source patterns.

In the paper we also briefly discuss other potential proxies such as precipitation and OLR and highlight the advantage of SST. Two tests corroborate where the correlation coefficients are a sound indicator of convective forcing. Firstly, we test whether fine-scale patterns in the correlation maps are caused mainly by the phase of the annual cycle of the SST and hence 
are not introduced artificially by enhanced annual mean SST. Secondly, the global distribution of GWMF is shaped both by various GW sources as well as the filtering and modulation of GWs by the background atmosphere while they propagate upward into the middle atmosphere. In order to distinguish the influence of GW sources from effects of favorable propagation conditions, we perform global GW ray-tracing modeling with a homogeneous and isotropic source distribution (Preusse et al., 2009a) based on the Gravity wave Regional Or Global RAy-Tracer (GROGRAT) (Marks and Eckermann, 1995; Eckermann and Marks, 1997). This global ray-tracing simulation is used to delineate the source and wind-filtering effects.

In our study, convective GW excitation is estimated using GWMF from the satellite instruments SABER (Sounding of the Atmosphere using Broadband Emission Radiometry; Mlynczak, 1997; Russell III et al., 1999) and HIRDLS (Gille et al., 2003, 2008) on a global scale. The use of longterm data sets of GWMF, including also mesospheric altitudes and the discussion of wind filtering with the aid of the GROGRAT model, distinguishes the present study from previous work such as Preusse and Ern (2005) and Wright and Gille (2011). By using SST we can also identify GW sources from which GWs have spread to wider regions. This is particularly important for the mesospheric data.

The structure of the paper is therefore as follows. The data and models are described in Sect. 2. Section 3 discusses the salient patterns of global distributions of stratospheric GWMF. In Sect. 4 we introduce the correlation method and determine the latitude range where the correlations can be used with confidence as indication of GW sources. After this rather technical approach, Sect. 5 interprets the findings in terms of source processes and oblique propagation. A summary is given in Sect. 6 .

\section{Data and models}

In this section, we briefly describe the data sets used for our analyses. GW data are taken from spaceborne infrared limb sounders (IRLS). These are compared to sea surface temperatures and precipitation values, which are used as proxies for convection. Results from GROGRAT modeling based on a homogeneous, isotropic source are also introduced and will be employed in Sect. 3 to investigate the influence of propagation effects.

\subsection{GWMF from spaceborne infrared limb sounders}

The SABER instrument was designed especially for measurements at higher altitudes ranging from the tropopause to well above $100 \mathrm{~km}$. It was launched on board the Thermosphere, Ionosphere, Mesosphere Energetics and Dynamics (TIMED) satellite in December 2001. It has operated continuously since January 2002. In this study, data from up to December 2010 are used. The SABER temperatures are derived from $15 \mu \mathrm{m} \mathrm{CO}$ infrared emissions (e.g., Mertens et al., 2004; Remsberg et al., 2008). The HIRDLS instrument was one of the core instruments on board the Aura spacecraft deployed in the Earth Observing System (EOS) program. The Aura spacecraft was launched on 15 July 2004, and HIRDLS temperature data of version V005 (Gille et al., 2008) are available for the period from January 2005 to December 2007. A detailed description of the GWMF data used in this study is given by Ern et al. (2011), and only a brief summary of the GW processing is given in the following paragraph.

In order to deduce GWMF, as a first step GWs are isolated by subtracting global waves with wavenumbers $0-6$. The resulting vertical profiles of temperature fluctuations are analyzed by a combination of the maximum entropy method and sinusoidal fits (Preusse et al., 2002). This results in vertical profiles of vertical wavelength, amplitude and phase of the GW structures. By comparing the phases of adjacent profiles, the horizontal wavelength in the direction of the measurement track is deduced (Ern et al., 2004) and the absolute value of GWMF is estimated. Since SABER and HIRDLS measure radiances integrated along the line of sight, the shortest horizontal wavelengths visible to these instruments are $\sim 100-200 \mathrm{~km}$ (Preusse et al., 2002, 2009b). Gravity wave momentum flux can be estimated only from profile pairs with a profile distance of less than $300 \mathrm{~km}$ and with well-matching vertical wavelengths. At each altitude this limits the number of GWMF values per day to approximately 350 values of GWMF for SABER and to approximately 3000 values of GWMF for HIRDLS.

\subsection{Sea surface temperature}

The optimum interpolation (OI) sea surface temperature (SST) monthly data is provided by the National Ocean and Atmospheric Administration (NOAA) with a horizontal resolution of $1^{\circ}$ longitude and $1^{\circ}$ latitude from December 1981 to December 2012 based on in situ and satellite data. The in situ observation data are from ships and buoys (both moored and drifting). The source of the in situ data changed at the end of 1997. Before 1998 they were obtained from the Comprehensive Ocean-Atmosphere Data Set (COADS) and after 1998 they have been obtained from the Global Telecommunication System (GTS). Advanced Very High Resolution Radiometer (AVHRR) satellite data enter the SST data set starting in late 1981. A small residual bias of roughly $-0.03^{\circ} \mathrm{C}$ still remains, although the satellite bias correction and the sea ice to SST conversion algorithm have already improved in version 2 (Reynolds et al., 2002).

\subsection{Precipitation}

Global Precipitation Climatology Project (GPCP) version 2.1 precipitation monthly data (1979-2012) with $2.5^{\circ}$ 
latitude and $2.5^{\circ}$ longitude spatial resolution from the NOAA/OAR/ESRL (Office of Oceanic and Atmospheric Research/Earth System Research Laboratory) Physical Sciences Division is used to investigate the relationship between convective activities and convective GWMF distribution in the stratosphere. This data set combines satellite data, rain gauges and ground-based radar. Precipitation observations are collected from over 70000 stations around the globe including Global Telecommunications System (GTS) reports and other worldwide or national data (e.g., Adler et al., 1994; Arkin and Meisner, 1987; Grody, 1991). Satellite data are merged according to their respective availability. Special Sensor Microwave/Imager (SSM/I) precipitation data are provided by the Defense Meteorological Satellite Program (DMSP, USA) satellites that fly in sun-synchronous low earth orbits (LEO). Precipitation estimated from observations of infrared (IR) radiation is based on the geostationary orbit (GEO) and LEO infrared satellite data (GEO-IR and LEOIR) obtained from the National Environmental Satellite Data and Information Service (NESDIS, USA), the Japanese Meteorological Agency (JMA) and the European Organisation for the Exploitation of Meteorological Satellites (EUMETSAT). In addition, the LEO data are obtained from the Atmospheric Infrared Sounder (AIRS) data from NASA Aqua and Television Infrared Observation Satellite Program (TIROS) Operational Vertical Sounder (TOVS) and OLR precipitation index (OPI) data from the NOAA series satellites. Further developments and calculations are performed by the Global Precipitation Climatology Centre (GPCC) of the Deutscher Wetterdienst and by the Climate Prediction Center of NOAA (e.g., Adler et al., 2003; Huffman et al., 2009).

\subsection{GROGRAT simulations}

Global ray-tracing simulations are performed in order to quantify the influence on the global distribution by filtering and modulation of GWs by the background winds and background stability (buoyancy frequency). The general set-up is described in detail by Preusse et al. (2009a) and only a brief summary is given here. Rays are launched at $5 \mathrm{~km}$ altitude. The GW spectral distribution is taken into account by launching a total of 14 different combinations of amplitude, phase speed and horizontal wavelength, each combination forming one spectral component. For each individual spectral component, rays are launched homogeneously and isotropically in eight directions every $2^{\circ}$ in latitude and every $5^{\circ}$ in longitude.

In order to produce global maps, GWMF values are averaged in overlapping bins of $4^{\circ}$ latitude and $10^{\circ}$ longitude for the total spectrum combined from all 14 spectral components. For this average, the contributions of individual spectral components are weighted. The respective weighting factors were determined by Preusse et al. (2009a) from comparisons of ray-tracing simulations with zonal mean GW variances from SABER observations and zonal mean GWMF from Cryogenic Infrared Spectrometers and Telescopes for the Atmosphere (CRISTA) observations. With launch distributions tuned in this way, the salient global features and the annual cycle are well represented. For the present run, background wind and temperature fields were taken from European Centre for Medium-Range Weather Forecasts (ECMWF) analyses. By means of data assimilation, these data provide a good representation of the actual state of the atmosphere up to an altitude of $40 \mathrm{~km}$ or higher and are therefore well suited to investigate the modulation of GW propagation conditions by changes in the wind and buoyancy frequency fields. We have modeled every third day for the years 2002-2010 and four local times for each day in order to average over the diurnal cycle.

\section{The physical reasons for the salient patterns in global GW distributions}

As a first step, we consider global maps of stratospheric GWMF at $25 \mathrm{~km}$ altitude. Based on previous studies, we explain how various sources of GWs, on one hand, and filtering and modulation of GWs by the background atmosphere, on the other hand, form the salient patterns seen in these global maps. The lowest altitude for which we can deduce reliable estimates from both instruments is $25 \mathrm{~km}$. For this lowest altitude the influence of propagation conditions is expected to be smallest and, accordingly, the influence of sources is expected to be largest.

Figure 1 shows global maps of GWMF for HIRDLS (upper row) and SABER (middle row) at $25 \mathrm{~km}$ altitude in January and July. Due to the higher number of GWMF values, a finer grid spacing was chosen for the HIRDLS data. HIRDLS data are given for the year 2006, whereas SABER data are an average over the years 2002 to 2010. Absolute values of GWMF from HIRDLS are about $40 \%$ lower than GWMF values from SABER. The difference corresponds to an amplitude difference of $20 \%$ and may be caused by different retrievals and the fact that SABER radiances start to become optically opaque at these altitudes. The differences between SABER and HIRDLS are within the errors stated in Ern et al. (2004). Furthermore, HIRDLS data represent a single year while SABER data represent a 9-year climatology. Different propagation conditions, for instance a varying phase of the quasi-biennial oscillation (QBO), modulate the strength of GWMF: according to Ern et al. (2014), the year 2006 shows average low-latitude GWMF while some other years such as 2005 show enhanced GWMF values, which are part of the SABER 9-year mean as well.

Apart from these differences in the absolute values, the distributions deduced from the two instruments agree well in their salient features. There are higher values of GWMF especially at high latitudes of the respective winter hemisphere. These GWs are caused by the polar night wind jets and topography. In the summer hemisphere subtropics, there are several centers of enhanced GWMF which are generated 

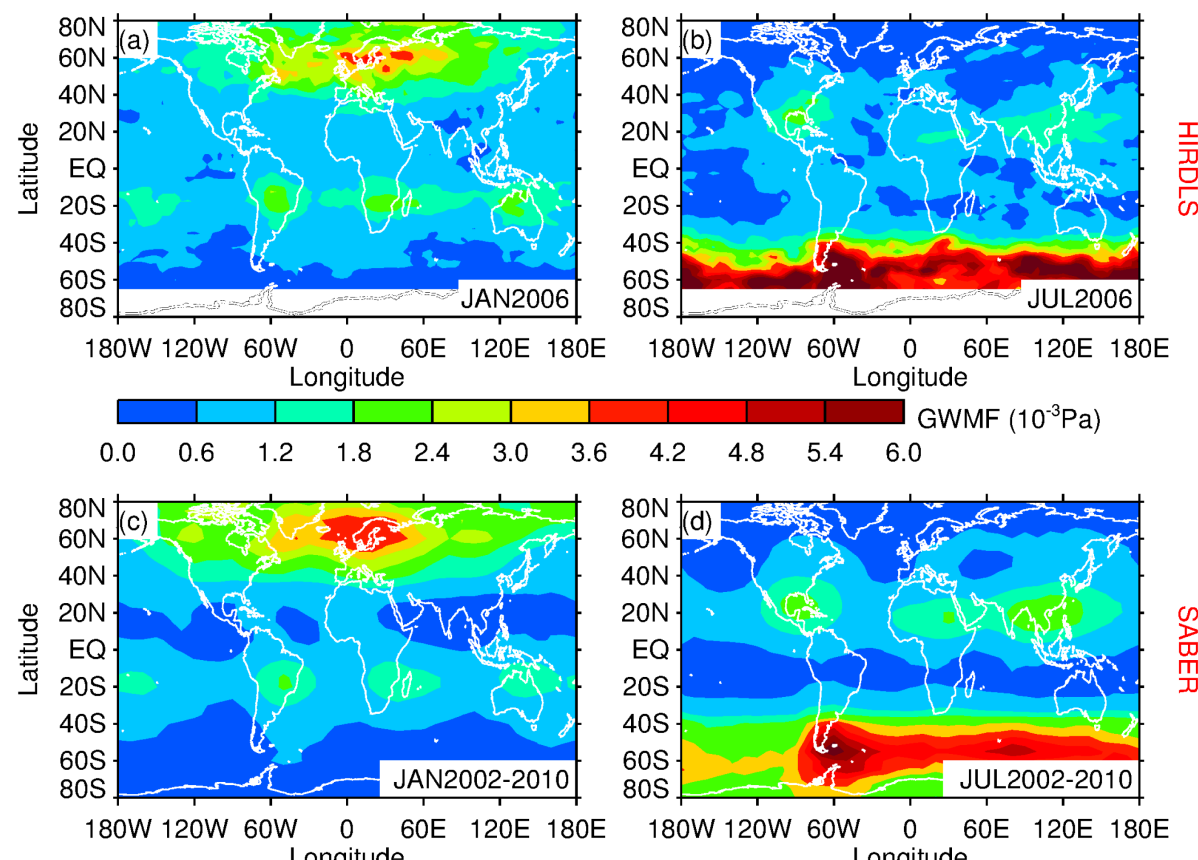

180W 120W 60W 0 Longitude
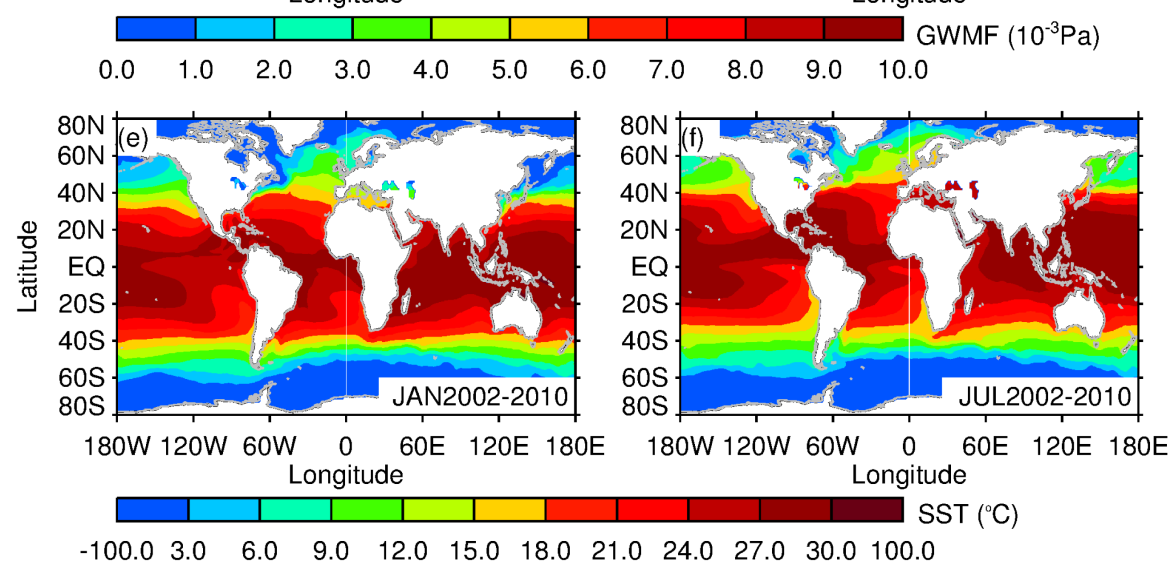

Figure 1. Global maps of GW momentum flux and SST. The left column shows values for January (southern summer) the right column for July (northern summer). GWMF for HIRDLS (upper row) and for SABER (middle row) are given at $25 \mathrm{~km}$ altitude. HIRDLS data are from 2006, while SABER data are the climatology from 2002 to 2010. Please note the different color bars indicating that GWMF from HIRDLS is about $40 \%$ lower than GWMF from SABER. SST data (lower row) are averaged for the years 2002-2010, same as for SABER GWMF.

by deep convection, for instance in monsoon regions, in the vicinity of Florida and, for the Southern Hemisphere, above the South American and African continents. These patterns are well known from previous studies (e.g., Jiang et al., 2004a, b; Preusse et al., 2009a; Ern et al., 2011). The fact that the salient features are very similar for the single year of HIRDLS observations and the 9-year SABER average indicates that similar patterns are formed in the various years considered in this study.

The basic structure of the stratospheric GWMF distribution is caused to a large degree by filtering and modulation of GWs by the background winds. For instance, Ern et al. (2006) and Preusse et al. (2009a) reproduced the enhanced GWMF in the winter polar vortices and also an enhancement of GWMF in the summer subtropics from a homogeneous source distribution. The cause behind enhanced GWMF values is favorable propagation conditions for GWs at these latitudes: GWs which propagate in the opposite direction to the main wind have higher intrinsic phase velocities, larger vertical wavelengths and can attain higher saturation amplitudes (for a detailed discussion see Preusse et al., 2006). In contrast, the wind reversal between tropospheric westerlies and stratospheric easterlies at mid- and high latitudes in summer is a very effective filter which removes a large part of the GW spectrum. These studies also show, however, that the subtropical maxima are underestimated if explained by wind filtering alone. While measurements indicate enhancements of about one order of magnitude in these 
presumably convective regions, modeling based on homogeneous sources can explain only enhancements of a factor of 2 to 3 . This indicates that sources play an important role as well. Maxima are found in active deep convection regions such as the Asian summer monsoon. Enhanced precipitation is presumably generated by strong events of deep convection which may excite GWs (Preusse et al., 2001a; Ern and Preusse, 2012; Wright and Gille, 2011). This is supported by convective source models, which indicate a similar longitudinal structure (Choi et al., 2009). Accordingly, there is some spatial correspondence between regions of enhanced precipitation and high GWMF as is shown in Appendix B. However, the correspondence is not very close for several reasons: firstly, GWs spread from their source regions while propagating upward. Secondly, monthly mean climatologies do not well distinguish intermittent strong precipitation associated with deep convection from continuous drizzle. Therefore, we do not use precipitation as a proxy for convection in the temporal correlations with GWMF. Furthermore, though OLR was employed in a study of convective GW excitation (Wright and Gille, 2011), for our study OLR is not well suited: Wright and Gille (2011) focused on the temporal evolution in regions for which the dominance of deep convection is well known. We, in contrast, are interested in a method to identify regions where convection may be an important GW source. While OLR (or cloud top height in general, cf. also Preusse, 2001; Spang et al., 2002) is a well-suited proxy for convective GW excitation in regions dominated by deep convection, drifting high-level clouds make it very problematic for global application. We discuss this in Appendix A. Instead of OLR and precipitation, we therefore use SST as proxy for convection and we make this use of SST plausible by first considering spatial patterns in the global distributions of GWMF and SST.

The low-latitude maxima of GWMF seen in Fig. 1 are in the respective summer hemisphere, i.e., in the southern subtropics in January and in the northern subtropics in July. This is consistent with the fact that subtropical deep convection forms predominately in the summer months. The maxima form over the continents as well as to the east of the continents but not on the western coasts.

Climatological values of SST averaged over the SABER period for January and July, respectively, are shown in Fig. 1e and f. Enhanced SST due to warm ocean currents is observed at the eastern coasts of the continents, and summer values are larger than winter values. In particular, in the subtropics of the respective summer hemisphere, GWMF is larger for regions where the SST is higher than for regions where SST is lower (cf. Fig. 4d below). In January, these higher SST values are found in Fig. 1e and $f$ in areas near Australia, in the South Pacific, and along the eastern shore of South America and Africa. These regions correspond with high GWMF values. The GWMF pattern matches the area of warm sea water very well, especially over the South Pacific centers. At the Equator and in the Northern Hemisphere GWMF remains small despite enhanced SST values. In July, the centers of higher SST move to the north and are located at the Gulf of Mexico and the western Pacific Ocean near Asia. The GWMF centers are also discovered over these regions and their extent corresponds well with the region of warm SST. GWMF is low in the vicinity of the Equator. Reasons may be the efficiency of the forcing, filtering by the background atmosphere and observational filter effects of HIRDLS and SABER. This is discussed in some detail in Appendix B. However, although the equatorial GWMF values are comparably low, they contribute a large part to the driving of the QBO and about half of the expected forcing of the QBO by GWs (Ern et al., 2014). This indicates that the measurements do not underestimate the equatorial GWMF particularly strongly.

Sea surface temperature was previously used by Preusse and Ern (2005) as a proxy for convection. This assumes that in regions of enhanced SST there is also an enhanced likelihood of convection. This assumption is made for the tropical region in general, but also for the warm ocean currents such as the Gulf Stream and the Kuroshio. By using SST, we restrict the investigated area to the oceans.

\section{Correlation analysis: technical concepts and tests for confidence}

The previous section indicates that the correlation of observed GWMF with SST can reveal convective GW sources. Still, the modulation and filtering of GWs by the background atmosphere may have an even larger influence on the largescale patterns of the global distribution than the sources have. However, localized patterns often reveal source processes.

In this section, we introduce global maps of temporal correlation between observed GWMF and SST. By removing the zonal mean from these maps of correlation coefficients, source processes are emphasized. Two potential reasons for misleading correlation patterns are discussed: first we consider whether an enhancement in the average SST in the region of the ocean currents may introduce patterns. Second, a homogeneous and isotropic GW source distribution is used to delineate the effects of filtering and modulation by the background atmosphere. Differences between these simulations and the real data indicate the latitude ranges in which the sources revealed by correlation analysis dominate. This is supported by comparison against precipitation as an independent quantity.

The temporal correlations between two quantities, for instance SST and GWMF, are based on monthly average global maps such as the maps of GWMF shown in Fig. 1a and b. For the 9-year SABER data set, 108 such maps exist. Consequently, for each specific grid point a time series consisting of 108 points is formed. This is correlated to the same time series of the convection proxy. In this way, we calculate a correlation coefficient for each grid point of the global maps. In cases where the maps are on grids of different spacing, 

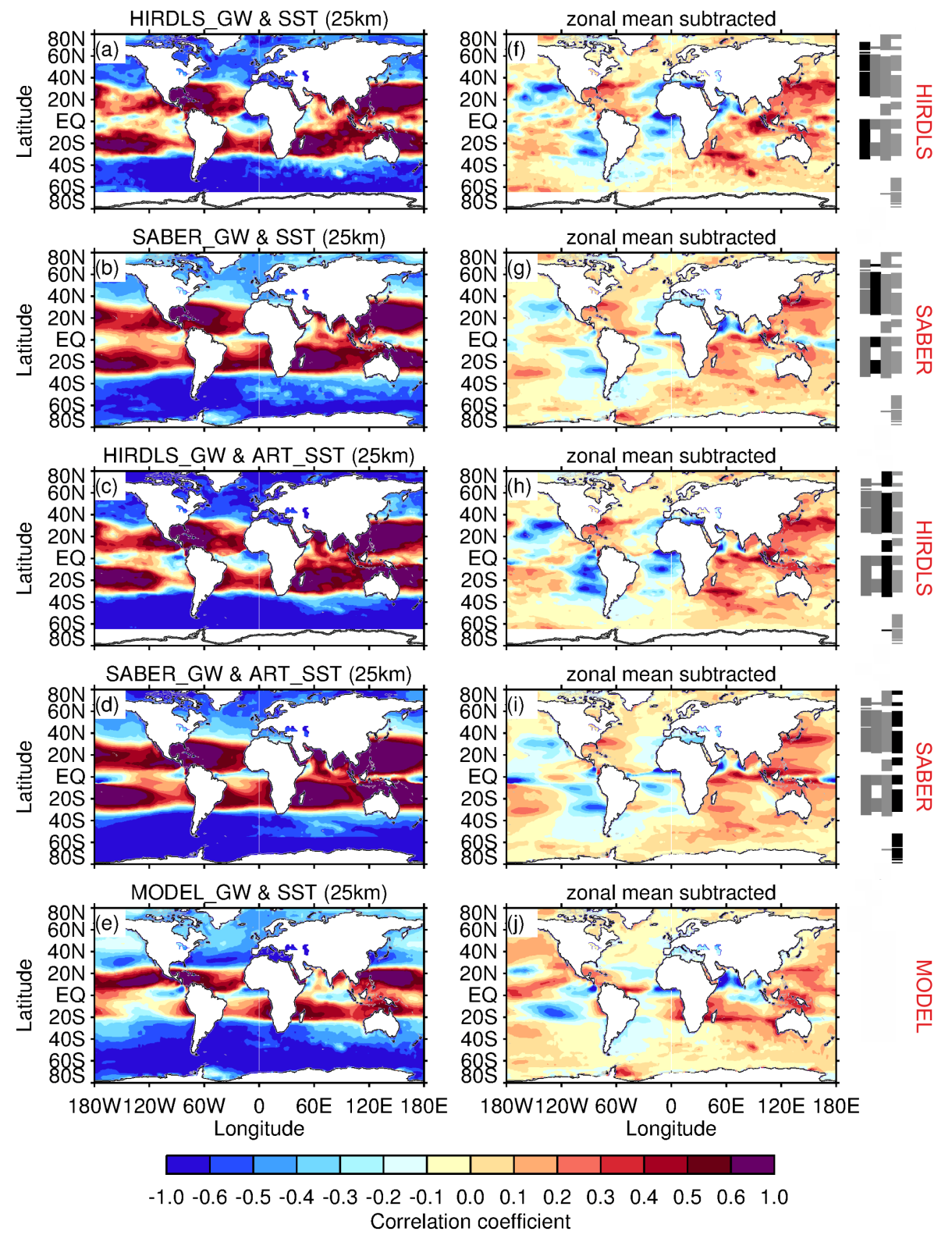

Figure 2. Global maps of correlation coefficients from temporal correlations. Correlation between time series of GWMF and of SST from various sources are calculated and presented in the left column. The middle column shows corresponding maps after zonal detrending. On the right side of the maps, an indication of confidence is given which represents the influence of sources on the distribution (cf. Sect. 4.3 and Fig. 3). In each row the indication bar deduced from the map in the middle column of this row is highlighted in black. The first row (a, f) shows correlations between HIRDLS GWMF and SST, the second row (b, g) shows correlations between SABER GWMF and SST, the third row $(\mathbf{c}, \mathbf{h})$ presents correlations between HIRDLS GWMF and artificial SST, the fourth row (d, i) presents correlations between SABER GWMF and artificial SST and, finally, the fifth row (e, j) shows correlations between a GROGRAT simulation and SST. For details see text.

the maps with the coarser spacing are interpolated to the grid with the finer spacing before calculating the correlations. For HIRDLS the same technique is used, but with only 36 monthly maps between January 2005 and December 2007 forming the time series.

\subsection{Correlation between observed GWMF and SST}

The spatial distributions of temporal correlations between SST and GWMF from HIRDLS and SABER are shown in Fig. 2a and b. In general, there are positive correlation coefficients in the subtropical regions (10 to $30^{\circ}$ of both hemispheres) and negative correlation coefficients at high latitudes (poleward of $30^{\circ}$ ). This structure reflects the large 

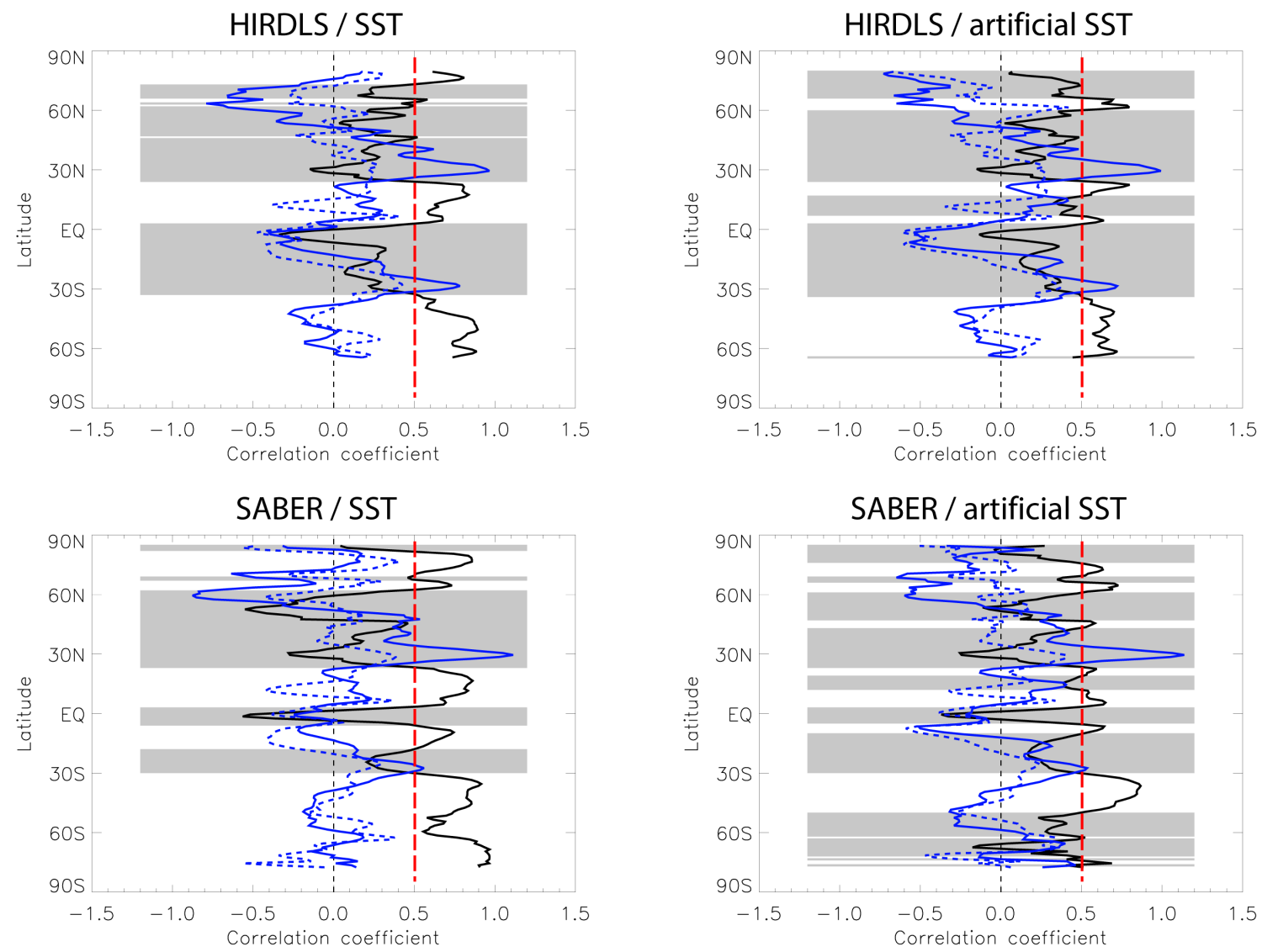

Figure 3. Latitude cross sections of the spatial correlation along one latitude circle between temporal correlations (black) of both observed GWMF and GWMF simulated by GROGRAT with SST, precipitation and temporal correlations (blue dashed) of observed GWMF with SST and the latter but corrected for the correlation between precipitation and the temporal correlation of GWMF simulated by GROGRAT with SST (blue). The gray shading indicates where the correlation between observed and simulated GWMF (i.e., the black line) is below a threshold of 0.5 .

influence of wind filtering and wind modulation on the distribution of GWMF in the stratosphere. In particular, the latitudinal structure is to a high degree given by the background wind fields. Seasonal changes of GWMF due to modulation by the zonal wind are in phase with the seasonal cycle of SST in the subtropics and out of phase at high latitudes. If higher SST/enhanced convection produces stronger GWMF, as expected, higher SST/enhanced convection should therefore result in more positive correlations in the subtropics, and it should result in less negative correlations than average at the higher latitudes. The localized effects are smaller than the modulation by the winds. In order to isolate the localized patterns, we take the values from the maps shown in the left column of Fig. 2, calculate the zonal means and subtract these zonal mean values from these maps. Such zonally detrended maps of residual correlations for HIRDLS and SABER are shown in Fig. $2 \mathrm{f}$ and $\mathrm{g}$. In regions with positive residual correlations, GWMF is enhanced at the same time as SST (and probably convection) during an annual cycle or other temporal variations. Patterns of enhanced correlation are found at the following locations: the northwest Pacific, around the Maritime Continent in a region extending from Malaysia and the western Indian Ocean to the north coast of Australia, above the Gulf of Mexico and along the Gulf Stream and over the southern Indian Ocean close to Madagascar. By subtracting the zonal average, longitudinal variability is highlighted and coherent patterns of more positive correlations due to higher SST/enhanced convection can also be followed over a larger range of latitudes, e.g., the Gulf Stream and the Kuroshio ${ }^{1}$, even though the sign of the correlation before subtraction of the zonal average changes at around $30^{\circ}$ latitude both for the Southern and Northern hemispheres.

\footnotetext{
${ }^{1}$ The correlation patterns over the Gulf Stream and the Kuroshio are oriented almost zonally and thus follow more closely the patterns of enhanced SST as seen in Fig. 4 rather than the actual mass transport of these ocean currents which would be oriented more in a northeast direction.
} 

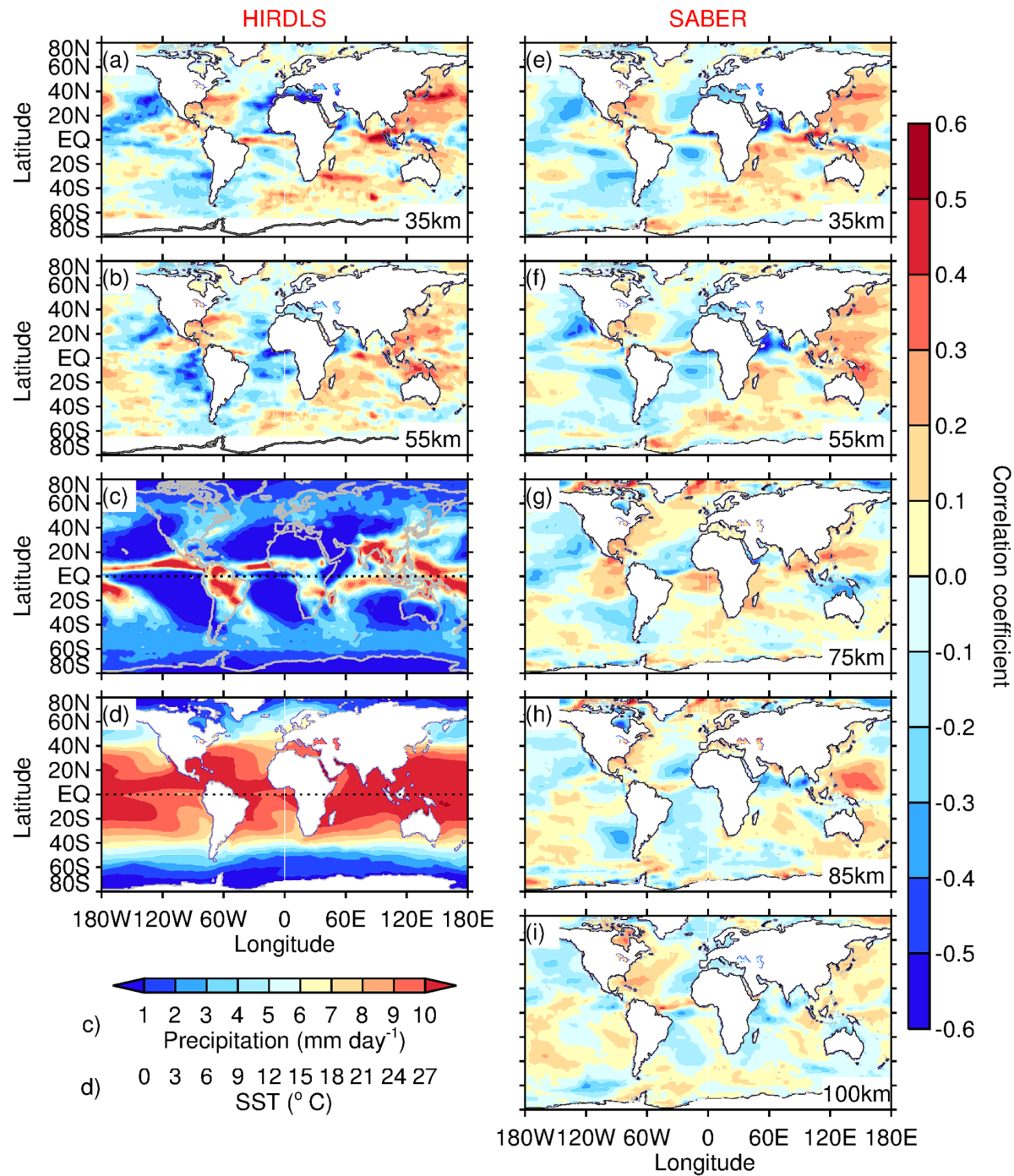

Figure 4. Global maps of zonally detrended correlations between SST and GWMF as well as summer composites of precipitation and SST. Panels (a) and (b) show zonally detrended correlations deduced from HIRDLS at 35 and $55 \mathrm{~km}$ altitude, the right column shows results from SABER for 35, 55, 75, 85 and $100 \mathrm{~km}$ altitude. For comparison, precipitation and SST distributions are given in panels (c) and (d). Both maps show the distributions of the respective summer hemisphere, i.e., they show July values for the Northern Hemisphere and January values for the Southern Hemisphere.

\subsection{Correlation between GWMF and artificial SST}

After removing the zonal mean, high correlation coefficients closely follow the warm ocean currents. This is physically plausible and enhances our confidence that they reflect GW sources. However, these regions also display enhanced SST in the annual average, which might project into the correlations. On the other hand, if the SST is mainly indicating the time of the convectively active season, patterns in correlations should be independent of the mean SST value and the amplitude of the SST variation. In order to verify this, an artificial SST is generated which at a given location is defined by a sinusoid of a 12-month period with an amplitude of 1 and minimizing/maximizing approximately at the same time when the SST minimizes/maximizes. Shorter or longer time variations than the annual cycle as well as the average value at this location are removed. The technical details and a figure visualizing the artificial SST are presented in Appendix C.

Temporal correlations between observed GWMF and this artificial SST are shown in Fig. 2c and d for the original correlations and in Fig. $2 \mathrm{~h}$ and $\mathrm{i}$ for the zonally detrended correlations. Figure $2 \mathrm{~h}$ and $\mathrm{i}$ reproduce almost exactly the features observed in Fig. $2 \mathrm{f}$ and g. This provides evidence that the agreement in the annual cycles of SST and GWMF is responsible for the correlation patterns. In addition, the fact that localized features are found in such regions where artificial SST is not locally structured provides evidence that these 

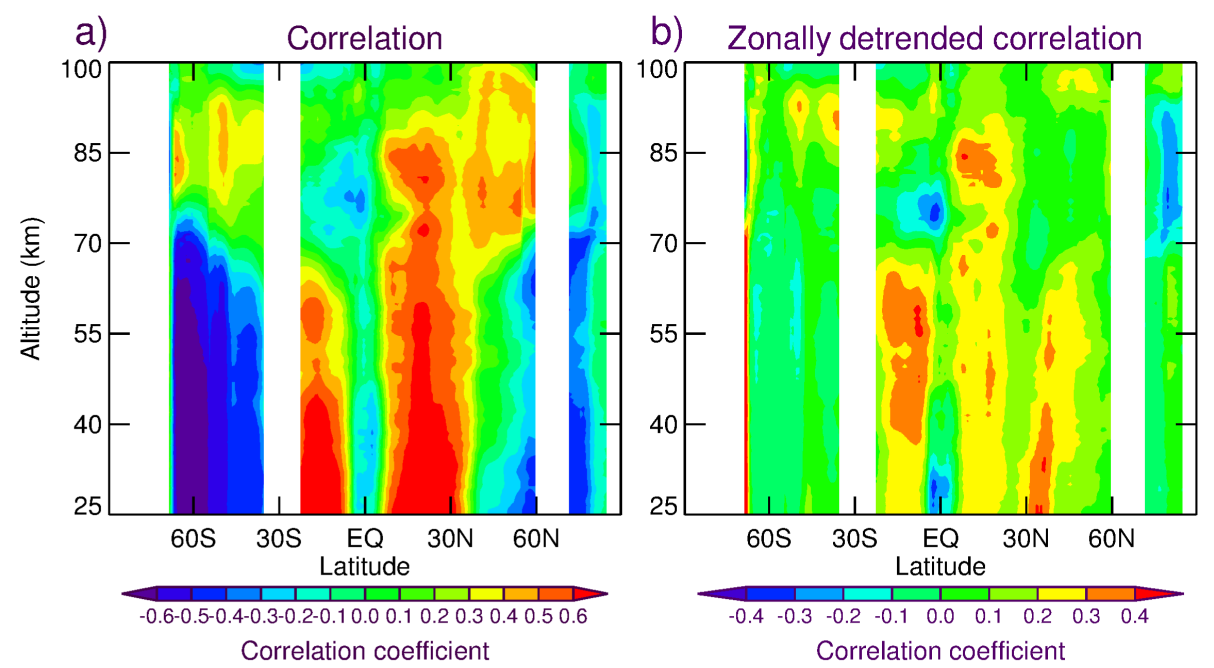

Figure 5. Altitude-latitude cross section of (a) correlation and (b) zonally detrended correlation between SABER GWMF and SST for $150^{\circ} \mathrm{E}$.

localized patterns are caused indeed by information which is contained in the GWMF data and that they are not introduced by features in the SST. However, a few patterns in the tropics need to be interpreted with care since close to the Equator artificial SST also shows localized patterns. The most prominent example is the streak of correlation between the western coast of Africa and the eastern coast of South America. This is a small-scale pattern in Fig. A3b, and though it corresponds well with precipitation, it may also be caused by a comparable annual cycle in the large-scale fields and in SST, i.e., the pattern may be incidental.

\subsection{Correlation between GROGRAT data and SST}

As discussed above, the chief uncertainty in interpreting global maps of correlations in terms of sources are modulation and filtering of GWs by the background atmosphere. Features which depend on latitude only are removed by subtracting the zonal mean. This highlights all structures which vary with longitude in the maps of residual correlations. It has been shown in previous studies (Manzini and McFarlane, 1998; Ern et al., 2006; Preusse et al., 2009a; Geller et al., 2013) that the general zonal structure and the annual cycle can be reproduced reasonably well by a homogeneous and isotropic launch distribution of GWs launched in the middle troposphere. It is essential that the waves are launched below the tropopause since the wind filtering in the tropopause region is decisive for the global distribution in the stratosphere (Ern et al., 2006). In this study, we use the setup of Preusse et al. (2009a) and extend it to the full 9 years of the SABER data (for description see Sect. 2.4). This allows us to evaluate which regions with high correlations are produced by the wind filtering/wave propagation effect. Only correlation patterns which are not generated by the propagation conditions are evidence of GW sources.
Correlations between GWMF from the GROGRAT experiment and SST are displayed in Fig. 2e and j. The simulated patterns seen in Fig. 2e should largely resemble the correlations from the real data in Fig. $2 \mathrm{a}$ and $2 \mathrm{~b}$ and the patterns in Fig. $2 \mathrm{f}$ should largely resemble the correlations from the real data in Fig. $2 f$ and $2 g$, if mainly favorable propagation conditions cause the high correlations.

As expected, we find a similar latitudinal structure of the correlation without the zonal mean being removed: the summer subtropical jets provide favorable propagation conditions at the same time when the SST is high as well, while at mid- and high latitudes propagation conditions for GWs are most favorable in winter, when SST is low. After removing the zonal mean, however, the distributions are almost completely different: for instance, we find negative correlations above the Gulf Stream and the Indian monsoon region and no recognizable pattern for the Kuroshio. Low correlations at the western coasts (cold water) of North America, South America, Africa and Australia are missing. Some patterns (Madagascar) are at the right longitude but wrong latitude. Some tropical features, however, such as the streak from Africa to South America (cf. Sect. 4.2) are similar to the features seen in observations. In addition, a feature at the Antarctic Peninsula seen in Fig. $2 \mathrm{~g}$ can be reproduced by the GROGRAT run in Fig. $2 \mathrm{j}$ as well.

Since it is difficult to distinguish similar and dissimilar patterns in the two maps, we use spatial correlations in order to identify latitudes which are indicative of convective sources. For each latitude, we correlate the longitudinal structure of the maps shown in Fig. $2 \mathrm{f}$ to $\mathrm{i}$ with the longitudinal structure of Fig. 2j. The results are shown by the black lines in the respective panels of Fig. 3. High (low) correlations correspond with a dominant propagation (source) effect. 
A threshold of 0.5 (red dashed line) is used to determine all the latitudes which are likely source-dominated. This is indicated by gray shading. The gray shading is reproduced as an indicator of confidence to the right of the maps in Fig. 2. For each row the indicators of all four combinations shown in Fig. 3 are reproduced; the one deduced from the map shown in this particular row is given in black, the other ones are shown in gray. The different indicators are largely consistent. Correlation with artificial SST indicates somewhat larger confidence than correlation with observed SST. For the latitude ranges $20-60^{\circ} \mathrm{N}$ and $0-30^{\circ} \mathrm{S}$, convective sources most likely dominate the features in the maps. High latitudes and, in particular, mid- and high latitudes in the Southern Hemisphere may not be interpreted with confidence in terms of sources. In the northern tropics, from 0 to $20^{\circ} \mathrm{N}$, many features seem to be generated by the background atmosphere as well. This does not mean that in the indicated regions convective sources are not important (likely they are), but it does mean that we cannot safely identify them.

\subsection{Test by independent precipitation data}

So far we have used a spatially smooth proxy, SST, to identify potential source regions of convective GWs. In addition, we have used a global GW simulation based on a homogeneous source to identify the latitudes for which the inferred source patterns are meaningful. We now compare these source patterns to precipitation, which is a proxy with very pronounced, localized patterns. Since we have not yet used this proxy, this provides an independent test for the inferred GW regions dominated by convective sources.

Figure 4c shows a composite of the summertime precipitation. The values are averaged over the respective calendar month of the 9-year SABER period. Values in the Northern Hemisphere show precipitation for July, while values in the Southern Hemisphere show precipitation for January. As discussed above, precipitation is not proportional to GW excitation strength, but strong precipitation in summer should provide some indication for GW excitation accordingly, on the summer hemisphere; most major features of GWMF in the stratosphere correspond with precipitation features in the troposphere in maps of individual months (cf. Appendix B). We now consider this more quantitatively for the maps generated by temporal correlations.

Patterns in Fig. 4c are even more localized than regions of convectively generated GWs in the stratosphere as identified in Fig. 2. This is expected as GWs propagate obliquely and can spread away from their source considerably. For instance, Jiang et al. (2004b), Choi et al. (2009), Preusse et al. (2009a) and Ern et al. (2011) found indications that GWs propagate on average several hundred kilometers poleward between their source and the mid-stratosphere. It is therefore expected that patterns of convective GWs in the stratosphere are larger than the patterns of sources in the troposphere.
Again we use correlation for a more quantitative comparison. Since the correlation maps in Fig. 2 indicate GW sources which are pronounced in summer, we compare these maps with precipitation in summer and correlate the composite map shown in Fig. 4c against the distributions in Fig. $2 \mathrm{f}$ to i. The result of this correlation is the blue-dashed line in Fig. 3. The indicated correlations are only small. Due to oblique propagation, GWs spread from their sources and regions of enhanced GWMF in the stratosphere are therefore much larger than regions of enhanced precipitation. In a correlation analysis, high precipitation matches high GWMF in the center of a convectively active region, but at the rim of this region, high GWMF in the stratosphere is located above low precipitation. The first strengthens the correlation, the latter weakens the correlation. Where the regions are sufficiently large, the center parts of the regions dominate and we expect a low positive correlation. In fact we find only low positive values for the southern and northern subtropics and a lack of correlations for most other latitudes.

However, source patterns inferred from real data are still much more similar to precipitation than a distribution generated through modulation by the background atmosphere from a homogeneous source. We use the temporal correlation between GROGRAT and SST shown in Fig. $2 \mathrm{j}$ as a reference, which omits the contribution of localized sources. When we correlate the distribution from Fig. $2 \mathrm{j}$ with precipitation, we find in part strong negative correlations. We use these correlations as a baseline: correlation coefficients more positive than this baseline indicate a similarity between precipitation and the inferred convective GW areas. Subtracting the baseline from the longitudinal correlations between observations and precipitation results in the solid blue lines in Fig. 3, which are positive from 20 to $50^{\circ} \mathrm{N}$ and from 10 to $40^{\circ} \mathrm{S}$. In particular, positive values are found for most regions where gray shading indicates that the correlation between SST and GWMF indicates GW sources. In this way, the results from the two measures support each other.

\subsection{Summary of the technical part}

We use SST as a proxy for the convectively active season. Correlating time series of observed GWMF with SST, we find two effects: first, a strong latitudinal structure induced by filtering and modulation of GWs due to the background atmosphere and, second, localized patterns which likely correspond with source processes. We emphasize the localized patterns by subtracting the zonal mean. Resulting global maps of detrended correlation coefficients show particularly high values along the warm ocean currents, such as the Gulf Stream and the Kuroshio, but also for the eastern coasts in the Southern Hemisphere. These patterns are consistent for a wider latitude range despite the fact that the zonal mean correlation reverses sign within this latitude range. The patterns resembling the ocean currents are physically plausible and hence raise confidence in the method. 
We have tested several contradictory hypotheses. First, we correlated observed GWMF with an artificial SST which retains only the phase information of the seasonal cycle. This test shows that the correlation patterns along the ocean currents are generated by the temporal variation of the GWMF and are not biased by the mean values of the SST. Second, we have correlated a simulation based on a homogeneous and isotropic source against SST. The results are dissimilar to those from observed GWMF for latitudes $20-60^{\circ} \mathrm{N}$ and 0 $30^{\circ} \mathrm{S}$. In these latitudes, we may exclude that the modulation of GWs by the background atmosphere causes the observed patterns. Finally, we have compared the inferred patterns of GWs from convective sources with precipitation and find that observed GWMF is much closer connected to precipitation than simulated GWMF based on a homogeneous source distribution, in particular for latitudes 20 to $50^{\circ} \mathrm{N}$ and from 10 to $40^{\circ} \mathrm{S}$. This supports the results from the confidence test.

\section{Physical interpretation of source patterns}

In the previous section it is shown that temporal correlation of observed GWMF with SST and subtraction of the zonal mean reveals the spatial distribution of convective sources, at least in the latitude range $20-60^{\circ} \mathrm{N}$ and $0-30^{\circ} \mathrm{S}$. In the current section we discuss the physical processes connected to these sources.

\subsection{Source patterns seen at $25 \mathrm{~km}$ altitude}

In Fig. 2 patterns of high correlations are found at the eastern coasts of the continents where warm ocean currents prevail, low correlations are found west of the continents where cold ocean currents are found. Particularly pronounced positive correlations are observed along the warm SST regions formed by the Gulf Stream and the Kuroshio. The assumed physical mechanism is that enhanced SST initiates convection which in turn excites GWs, so on the one hand this could be due to a direct relationship between favorable conditions for convection in these regions and excited GWs. On the other hand, the strong correlation in these two local regions as well as patterns of positive correlations in the vicinity of Madagascar and west of Australia may be partly related to GWs excited by tropical cyclones, given that these regions are the major pathways of typhoons and hurricanes, respectively. Climatologies of typhoon tracks can be found, for instance, in Knapp et al. (2010), Hirata and Kawamura (2014), and references therein. The deep convection in tropical cyclones is a well-known source of convective GWs (e.g., Preusse, 2001; Kim et al., 2005, 2009) visible to various satellite instruments. In the numerical modeling study of Typhoon Saomai (2006), Kim and Chun (2010) estimate the absolute GWMF of typhoon-generated GWs at $25 \mathrm{~km}$ altitude for the period of 7-10 August 2006. During the developing period, the GWMF reaches its maximum of about $3.5 \mathrm{mPa}$ over $24 \mathrm{~h}$. On average they found $2.8 \mathrm{mPa}$ for $72 \mathrm{~h}$ including developing, mature and decaying stages. The simulated absolute GWMF is slightly larger than that observed in July 2006 from HIRDLS and similar to that observed from SABER in July averaged over 2002-2010, as shown in Fig. 1. Comparison of GWMF from observations and numerical simulations is always subject to uncertainties. However, the large values simulated indicate that typhoon-generated GWs can contribute to GWMF in the stratosphere near major pathways of hurricanes and typhoons. The strong correlation between SST and GWMF near the Gulf Stream and Kuroshio shown in Fig. 2 supports this possibility further, considering the positive correlation between typhoon activity and SST in general (Emanuel, 2005; Hoyos et al., 2006). On the other hand, tropical cyclones are exceptional events and the simulated values are not sufficiently large such that tropical cyclones could be the only convective sources for GWs in these regions.

As discussed in Sect. 4 the confidence of the correlation patterns in the latitude range 0 to $20^{\circ} \mathrm{N}$ is low. In this region we find several plausible features, but they are also contained in the simulation based on a homogeneous source distribution. One reason therefore could be a dominance of filtering and modulation by the background atmosphere. However, in the tropics also the relationship may break down that enhanced SST leads to enhanced convection: for instance, there is a small region of negative correlation coefficients east of New Guinea. In this region SST sometimes rises above $30^{\circ} \mathrm{C}$. For such high SST convection may be actually reduced (Meenu et al., 2012). It is, however, also possible that the large-scale circulation in this tropical region is of greater importance than the enhanced SST (Meenu et al., 2012).

\subsection{Correlation at higher altitudes}

At higher altitudes the seasonal cycle of the global background winds is much stronger than at the altitude of $25 \mathrm{~km}$ considered so far. Therefore, it could be assumed that variations in GWMF due to variations of the sources are attenuated more and more at higher altitudes by the dominating effect of the background winds and modulation due to the buoyancy frequency. An interesting question is therefore, up to what altitudes can variations of the GW sources themselves be identified in GWMF observations, i.e., can we identify convectively generated waves in the upper stratosphere and mesosphere? Figure 4 compares the summertime values (July for the Northern Hemisphere and January for the Southern Hemisphere) of precipitation (Fig. 4c) and SST (Fig. 4d) with the temporal correlation between SST and GWMF at various altitudes between 35 and $100 \mathrm{~km}$ altitude. For the correlations, the left (right) column shows results from HIRDLS (SABER), respectively. We find that the important features, such as enhanced GWMF at the eastern coasts and reduced GWMF at the western coasts, as well as an abundance of convective GWs above the warm ocean streams, persist well up to stratopause altitudes at least. The signal of some of the 
tropical rainbands even strengthens with altitude. This could be caused by the fact that shorter horizontal wavelengths contribute more strongly to the GWMF at these altitudes, but it could also be a coincidental mapping of the fine-scale patterns in the annual cycle of SST. Note that the test of correlating SST with GWMF from the GROGRAT simulation shows that at these latitudes propagation conditions may result in similar features.

At altitudes above $55 \mathrm{~km}$ only SABER provides GWMF. We again tested the GWMF correlation with artificial SST, not shown, and find robustness in the main patterns; with increasing altitude differences become larger. Between 55 and $85 \mathrm{~km}$ many features seen at lower altitudes are lost. In the upper mesosphere/lower thermosphere (MLT), only the strongest features persist, i.e., for the Northern Hemisphere, the Gulf Stream and the Kuroshio and for the Southern Hemisphere, Madagascar and the eastern coast of Australia. Several features in the tropics, such as positive correlations at the western coasts of America and Africa, are not stable. They appear at $75 \mathrm{~km}$ altitude, but negative correlations are found for $65 \mathrm{~km}$ (not shown) and $85 \mathrm{~km}$ at the same places. It should be noted that even at low altitude the influence of propagation conditions is strong and, in addition, that SST is relatively structured. Therefore, in Sect. 4.3 the correlations in tropical regions were not considered as a good indicator of sources, even at low altitudes. At mesosphere altitudes, tropical dynamics are dominated by tides, both migrating and non-migrating. Tides influence the saturated part of the GW spectrum via the buoyancy frequency (e.g., Preusse et al., 2001b). Correlation patterns alternating between positive and negative correlations with a wavelength on the order of $20 \mathrm{~km}$ (a typical wavelength of a tide) may therefore be an indication of tidal modulation.

The patterns of positive correlation above Florida and the Gulf Stream as well as the Kuroshio seem to be gradually shifted poleward between the lower stratosphere $(25,35 \mathrm{~km})$ and stratopause $(55 \mathrm{~km})$ continuing into the mid-mesosphere. In order to show this more clearly, we present an altitudelatitude cross section of the correlation and the zonally detrended correlation for $150^{\circ} \mathrm{E}$ in Fig. 5. We chose this longitude for two reasons: first, it is still in the center of the region of enhanced correlation due to the Kuroshio and second, at this longitude there are comparatively few land masses and we obtain a reasonably well-covered cross section.

Figure 5a shows the correlations between GWMF and SST for $150^{\circ} \mathrm{E}$. Patterns are largely dominated by the propagation conditions. In the subtropics, GWs find favorable propagation conditions due to the subtropical jets in summer and, accordingly, correlations in the stratosphere are strongly positive. At higher latitudes, GWs are filtered in summer because of the wind reversal between tropospheric westerlies and stratospheric easterlies, but experience favorable propagation conditions in winter when both tropospheric and stratospheric winds are westerlies. Accordingly, correlations in the stratosphere are strongly negative. Around $75 \mathrm{~km}$ the seasonal cycle of GWMF is reversed. This is well known from radar (Hoffmann et al., 2010) and satellite observations (Krebsbach and Preusse, 2007; Preusse et al., 2009a) and can be reproduced by models (Hoffmann et al., 2010; Preusse et al., 2009a). At high latitudes, this is likely an effect of the relative wind filtering of slow and fast waves, and at midlatitudes oblique wave propagation may contribute as well. The global structure in Fig. 5a is consistent with this explanation.

The zonally detrended correlations in Fig. 5b highlight patterns which are likely due to localized sources. Two maxima around $15^{\circ} \mathrm{S}$ and $15^{\circ} \mathrm{N}$ could be both due to sources or modulation of the propagation conditions by the background atmosphere (see discussion above). The maximum around $30^{\circ} \mathrm{N}$ at $25 \mathrm{~km}$ is due to the Kuroshio and a continuous poleward tilt is clearly observed. At $70 \mathrm{~km}$ altitude, this maximum is centered around $50^{\circ} \mathrm{N}$. Some signatures between 80 and $90 \mathrm{~km}$ altitude around $60^{\circ} \mathrm{N}$ may be connected to this as well, but this is somewhat speculative.

The poleward tilt of the convective maxima is consistent with previous investigations of SABER measurements and global modeling. Ern et al. (2011) showed time series of GWMF at 30 and $70 \mathrm{~km}$ altitude. They found that the summer maxima located in the subtropics in the lower stratosphere are observed to be shifted poleward for higher altitudes. This shift corresponds with the poleward tilt of the jet. The propagation of GWs from regions of pronounced convective forcing and the propagation of the waves into the jet may also play an important role for the jets and the excitation of the quasi 2-day waves (Ern et al., 2013). Poleward propagation was identified by other observations before (Jiang et al., 2004b; Wu and Eckermann, 2008) and can be explained by oblique wave propagation of waves with a meridional component of the wave vector (Choi et al., 2009; Preusse et al., 2009a). The effect is enhanced by the horizontal refraction of GWs towards the jets (Preusse et al., 2009a; Sato et al., 2009; Ern et al., 2011; Kalisch et al., 2014).

The altitude-latitude cross section of Fig. 5a indicates tidal modulation of GWs around the Equator: correlations alternate between positive and negative values for altitudes of $70 \mathrm{~km}$ (positive), $80 \mathrm{~km}$ (negative), $95 \mathrm{~km}$ (positive) and $100 \mathrm{~km}$ (negative). The structure is centered around the Equator and the width is around $10-15^{\circ}$. The fact that the phase shifts between Fig. 5a and $\mathrm{b}$ indicates that this is both a local as well as a global phenomenon. All these facts match the solar tides very well (e.g., Oberheide et al., 2000).

\section{Summary and discussion}

Convectively generated GWs are important for the dynamical coupling among the different layers of the atmosphere. In particular, it will be helpful for further studies to identify the contribution of convective forcing to the global distribution of GWs solely by observations. In this way, we do not 
depend on the individual model chosen or on tuning parameters in the model. Identifying regions for which convective GW excitation is an important source is a difficult task since the GW distribution in the stratosphere and mesosphere depends on filtering and modulation of the GW spectrum by the background winds as well as on the sources. The most promising way to isolate GW sources is therefore to correlate time series of measured GWMF values with proxies of convective forcing. We have shown in this study that convective forcing is indicated when the temporal evolution of the measured GWMF matches the evolution of the convective proxy. The choice of the proxy is not trivial. In this paper, we also briefly discussed the suitability of precipitation and OLR. We chose SST because enhanced SST is favorable for the generation of convection and because its patterns are of reasonably large scales to also capture GWs spreading by oblique wave propagation from their immediate source regions. The current investigation is distinguished from the earlier work of Preusse and Ern (2005) in that it uses (a) GWMF, (b) a much longer time series and (c) data up to the MLT. The global distribution of the temporal correlation of GWMF with SST was investigated. While the latitudinal structure is to a large degree given by the background winds, the structure in the longitudinal direction is primarily given by the sources, in particular in the latitude ranges of $20-60^{\circ} \mathrm{N}$ and $0-30^{\circ} \mathrm{S}$. This is corroborated by a detailed discussion of the data and by means of artificial SST data and modeling results from a 9year global GW ray-tracing run. We therefore isolated source effects by subtracting the zonal mean values from the correlation results.

The main findings of our analysis are

- The results from 3 years of HIRDLS and 9 years of SABER agree very well. Obviously, the patterns due to the annual cycle are quite stable and are much more strongly pronounced than interannual variability.

- Warm ocean currents are a major cause of convective GWs over ocean. We find, both for the Northern and the Southern hemispheres, enhanced convective gravity wave (CGW) activities along the eastern coasts of the continents above warm ocean currents and reduced CGW activities along the western coasts of the continents above cold ocean currents. This effect might not be caused by SST alone; the tropospheric circulation might contribute as well.

- The warm ocean currents in the Northern Hemisphere are much stronger than the warm currents in the Southern Hemisphere (Ishikawa et al., 1997). Accordingly, the patterns of the Gulf Stream and the Kuroshio are the clearest signature in the global maps.
- Further important sources of CGWs are in the regions around India (Indian monsoon) and the Maritime Continent. In a small region east of New Guinea, temperatures exceeding $30^{\circ} \mathrm{C}$ may actually lead to reduced convection and an anticorrelation.

- Correlation patterns are very stable up to at least $65 \mathrm{~km}$ altitude. Some weaker patterns are lost between $75 \mathrm{~km}$ and $85 \mathrm{~km}$ altitude, but the salient features of the Gulf Stream and the Kuroshio can be observed even in the MLT.

- There seems to be a poleward shift of convective patterns due to oblique wave propagation.

Based on several independent data sets, these results confirm that CGWs are important for the dynamical coupling of the lower atmosphere with the various layers of the middle atmosphere, i.e., the stratosphere, mesosphere and MLT. The evidence is based on observations and largely independent of modeling and model assumptions. The evidence presented shows that, in contrast to earlier implementations (Beres et al., 2005), CGWs are also important for mid- and high latitudes, for instance over the Gulf Stream and the Kuroshio. In a changing climate, SST rises (Purkey and Johnson, 2010; Balmaseda et al., 2013) and hence, at a first glance, a stronger forcing of CGWs would be expected. The region east of New Guinea, however, may be an example that from a certain point, CGWs would even be reduced if a SST threshold of $30^{\circ} \mathrm{C}$ is exceeded. Also, although convective GW excitation may become more frequent, deep convection may decrease. The example of the ITCZ shows that in this case GWMF, at least the part visible to satellites, would decrease as well. Comparisons of different climate models (Coupled Model Intercomparison Project Phase 5) indicate that the future development of convection and its organization is highly uncertain. However, parameterized CGWs should change in accordance with the changes in precipitation and its organization. Reliable climate predictions need to include the full climate feedback of CGWs by appropriate implementation of CGW excitation in climate models. The experimental data sets described here can help to constrain such CGW parameterizations. 


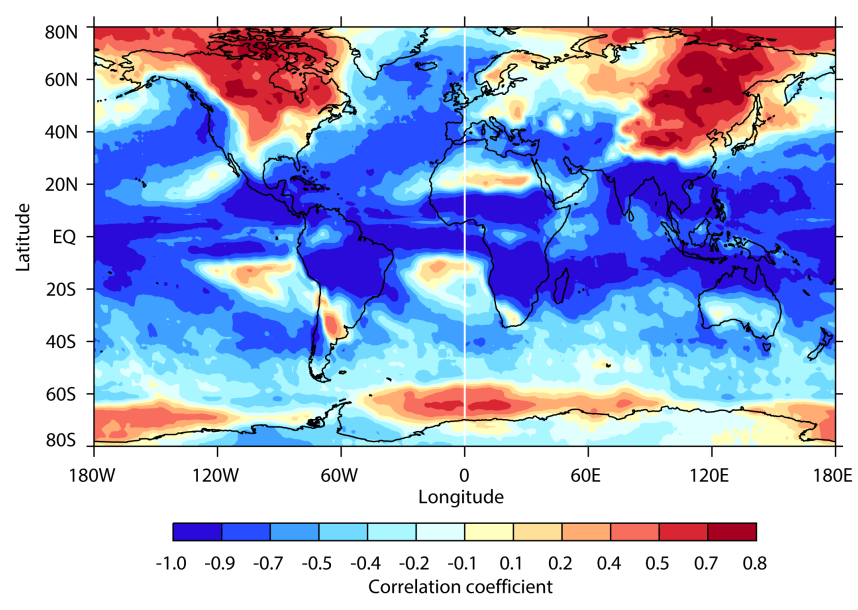

Figure A1. Global map of the temporal correlation between OLR and precipitation. In regions where OLR is a good proxy for convection, a strong negative correlation is expected.

\section{Appendix A: Suitability of OLR as a proxy for convective GW excitation}

The term outgoing long-wave radiation (OLR) denotes infrared radiation observed from the top of the atmosphere, for instance from a satellite, for nadir observation geometry. In general, that is, with the exception of polar stratospheric clouds (PSC), it is dominated by radiation from the troposphere. As tropospheric temperature decreases with altitude, OLR can be taken as a measure of the effective source altitude of the radiance. In particular, in the presence of optically thick clouds, OLR may be converted into a measure of the cloud top altitude. High cloud top altitudes may indicate deep convection. Accordingly, high cloud top altitude has been used as a proxy for convective wave generation in previous studies (Ricciardulli and Garcia, 2000; Preusse, 2001; Spang et al., 2002; Wright and Gille, 2011). Strong convection generates high-reaching clouds, but high-level clouds may be also generated by different processes, as the extreme example of PSCs elucidates. In studies which focus on monsoon regions, convective clouds dominate. In addition, in their outflow high-reaching convective clouds generate drifting high-level clouds (e.g., Spang et al., 2002). These clouds are opaque at high altitudes, i.e., cause low OLR values, but do not indicate convection and the corresponding latent heat release which could excite GWs. In the convective region itself, the time dependence on scales of weeks or months is the same and temporal correlation in these regions works well (Wright and Gille, 2011). In the tropics, a threshold may be employed to identify only very deep convection (Ricciardulli and Garcia, 2000; Preusse, 2001). However, thresholds do not identify convective clouds with lower cloud top heights which release latent heat and may therefore generate convective GWs nor can they be easily applied for the extratropics. However, if convective clouds dominate other high level clouds, they could still be a suitable proxy globally. Therefore, we investigated the suitability of OLR as a convective proxy in Fig. A1.

Figure A1 shows the global map of the temporal correlation between OLR and precipitation (see Sect. 4.1 for a description of the method). The higher the cloud top is, the lower is the corresponding tropospheric temperature, and the smaller is the OLR. Thus, we expect strong negative correlation between OLR and precipitation where OLR is a good proxy for precipitation and no correlation or even positive correlation for regions where OLR is a poor proxy for precipitation. Correlations are excellent for the Indian Monsoon, and tropical/subtropical South America and Africa. These are the regions where Wright and Gille (2011) found good correlations between OLR and stratospheric GWs. The region around Florida shows good, though not excellent, correlation between OLR and precipitation. Correlations are zero or even positive, however, in the North American monsoon region around California, a region where Wright and Gille (2011) also failed to explain stratospheric GWs by OLR. In general, in the extratropics the picture is very mixed with strong positive (that is poor) correlation for instance over the whole North American continent; even in the vicinity of the Equator there are some regions where the correlation breaks down. As a whole, this makes OLR an unsuitable proxy for a global survey by temporal correlation.

\section{Appendix B: Spatial co-location of GWMF and precipitation}

Spatial correspondence between GWs and precipitation has been discussed before in several studies. We here show the correspondence for the GWMF data used in this study. In Fig. A2, the global distribution of average diurnal precipitation (color) is compared with GWMF at $25 \mathrm{~km}$ (contour lines). The upper left panel shows HIRDLS data and precipitation in January 2006, and the upper right panel shows HIRDLS data and precipitation in July 2006. In the lower row, SABER data and precipitation are averaged for the respective January and July values for the years 2002 to 2010 . In January, in the Southern Hemisphere, maxima of GWMF are found for South America, Africa and Australia, the latter extending over the ocean further to the east and even exceeding the dateline, up to $150^{\circ} \mathrm{W}$. These maxima correspond well with maxima in rainfall at the same longitudes and similar latitudes. A main band of precipitation in the vicinity of the Equator does not correspond with any maxima in GWMF, however. We will discuss this low GWMF in the tropical regions below in this section. In the subtropical band GWs are Doppler-shifted by the subtropical jet to higher intrinsic phase speeds and therefore gain larger vertical wavelengths and larger amplitudes. In general, the location of the GWMF maxima appears to be shifted about 5 to $10^{\circ}$ southward with respect to the precipitation maxima. 

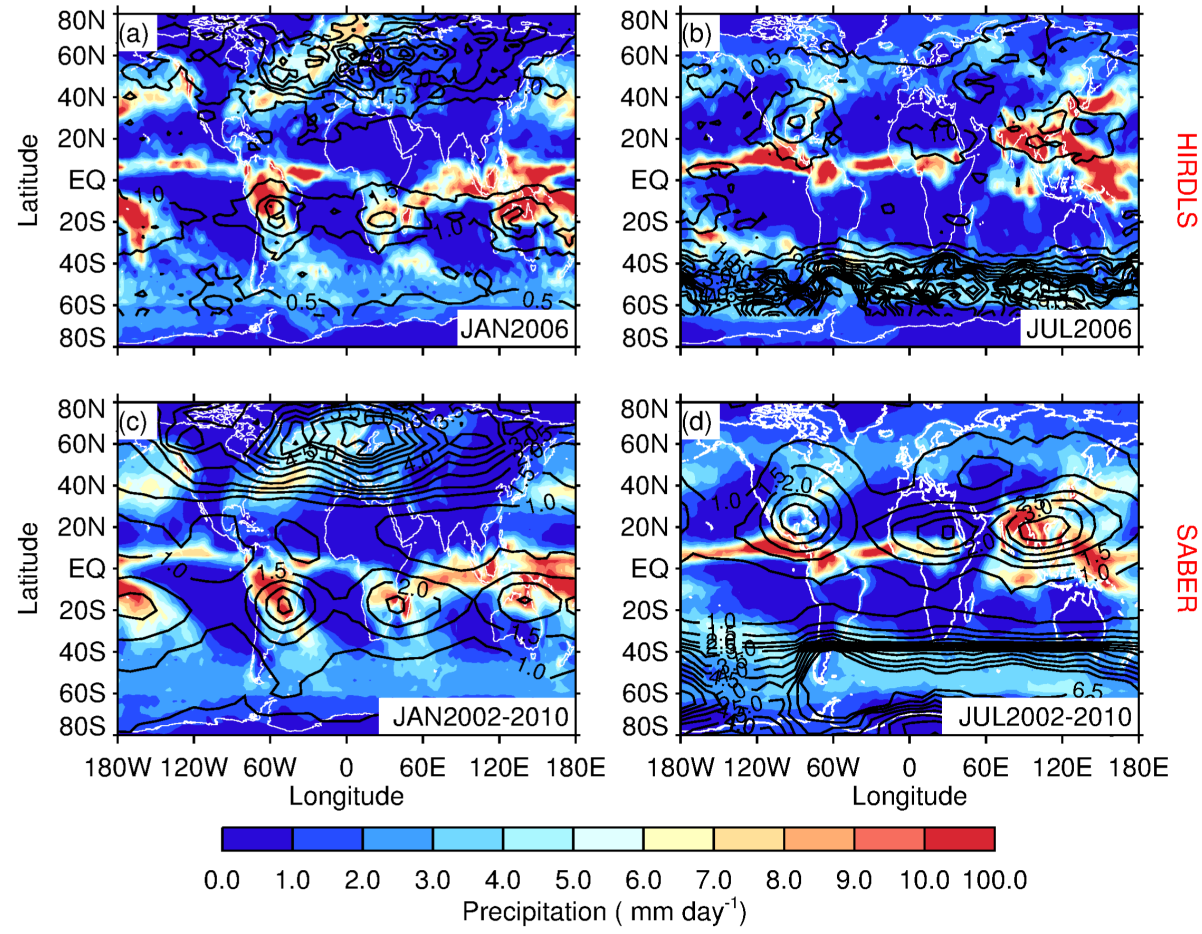

Figure A2. Global distribution of precipitation (colored, $\mathrm{mm} \mathrm{day}^{-1}$ ) and GWMF (contour lines, mPa) at $25 \mathrm{~km}$ from HIRDLS (upper panels, year 2006) and SABER (lower panels, averaged from 2002 to 2010) in January (left column) and July (right column).
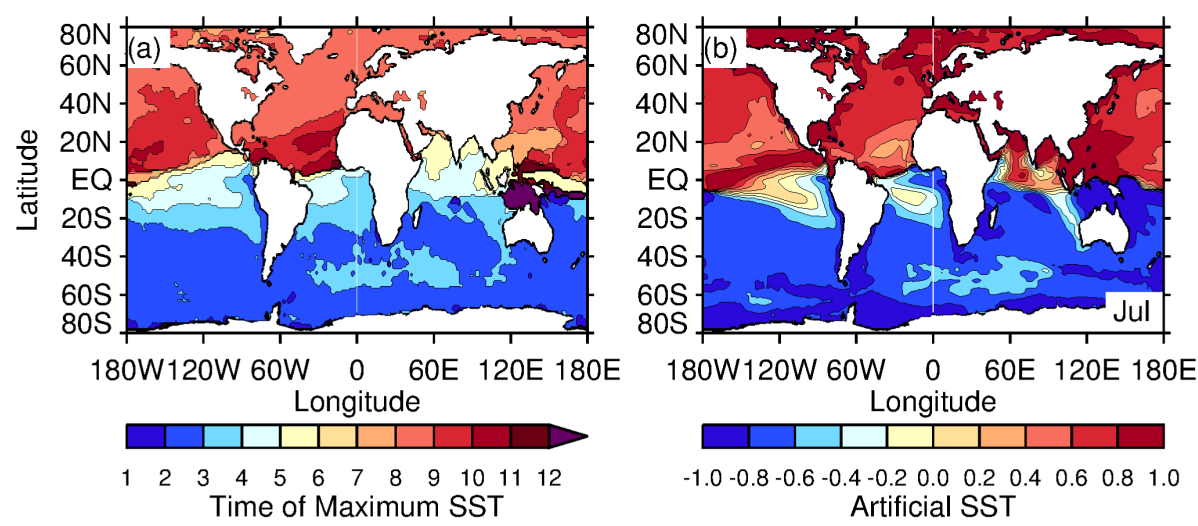

Figure A3. Visualization of the artificial SST generated from the annual cycle component of a fit to real SST data (for details see text). Panel (a) shows the calendar month when the annual cycle takes its maximum, panel (b) shows, for the example of July, the global distribution reconstructed from the annual cycle. Since the amplitude is normalized to 1 everywhere, panel (b) closely matches the structures of panel (a); the distribution for January is the inverse of panel (b).

In July, in the Northern Hemisphere, we again find an equatorial band of precipitation which has no counterpart in GWMF. Further to the north, we find precipitation over the Gulf of Mexico (in particular in the vicinity of Florida) and in the Asian monsoon which corresponds with centers of GWMF. Precipitation in the Asian monsoon is stronger, but the GWMF corresponding to these two convective centers is of approximately equal strength. A third weaker maximum is observed over Africa. All three maxima are also identified by Wright and Gille (2011). They found that the Asian monsoon maximum is much more strongly pronounced than the maximum over North America. However, it should be noted that the maximum over the southeast United States (i.e., centered around Florida) extends to $40^{\circ} \mathrm{N}$ in Fig. A2 and is therefore only partly represented in the 10 to $30^{\circ} \mathrm{N}$ average presented by Wright and Gille (2011). In general, for the Northern Hemisphere, the location of the GWMF maxima appears to be shifted poleward with respect to the precipitation maxima.

Discrepancies between the location of precipitation (or diabatic heating) maxima and the location of the GWMF 
maxima in the stratosphere can be explained by three factors. First, GWMF at the cloud-top level is determined by the basic-state wind, the buoyancy frequency from the surface to the cloud top and the vertical structure of convective sources. In the model of Song and Chun (2005), this is realized by a spectral combination of the convective source and a wave-filtering and resonance factor (WFRF). Much smaller (larger) values of WFRF in the ITCZ (in the subtropics) result in weaker (stronger) GWMF near the Equator (subtropics). This has been shown clearly by Choi and Chun (2011; Fig. 7), Choi and Chun (2013; Fig. 2) and Choi and Chun (2014; Fig. 9).

Second, filtering by the background flow from the cloud top to the target height can cause differences between the locations of the GWMF maxima and precipitation maxima. In particular, changes in the background wind in the equatorial middle atmosphere with various timescales, such as semiannual and annual cycles and QBO, allow different parts of the whole GW spectrum, presumably generated by convective clouds, to propagate to the target altitude. This is strongly dependent on the location. Therefore, it is necessary to jointly consider the changes in convective source spectrum and background flow in order to explain the observed GWMF precisely.

Third, oblique propagation of GWs can cause the difference between the source region and observed GWs in the middle atmosphere. GWs propagate horizontally as well as vertically, and this causes the difference between the source location in the troposphere and the observed GWs in the middle atmosphere. This has been shown from observations (Jiang et al., 2004b; Ern et al., 2011, 2013) as well as modeling studies (Choi et al., 2009; Preusse et al., 2009a). For instance, Song and Chun (2008) developed a ray-based convective GW drag parameterization and showed that GWs that are launched at tropical locations generated by convective sources with 201 wave packets in the west-east and northsouth directions propagate more than $20^{\circ}$ horizontally in the middle atmosphere within 1 day of integration of the Whole Atmosphere Community Climate Model. This demonstrates a likelihood of a significant horizontal departure of GWs from their source location during their propagation into the middle atmosphere, which is shown in Fig. A2. The relative influence of source and propagation is discussed in detail in Sect. 4.3; oblique propagation is discussed in Sect. 5.2.

The pronounced precipitation maximum of the ITCZ does not correspond with a maximum in GWMF, neither in the SABER or HIRDLS data nor in data of the Microwave Limb Sounder (MLS) or of infrared nadir observations by the Atmospheric Infrared Sounder (AIRS). Different explanations for this puzzling fact were offered by several studies, which are briefly summarized below.

Previous studies (e.g., Zhang, 1993) revealed that tropical deep convection remains weak and is rarely observed for a SST of less than $26^{\circ} \mathrm{C}$ and that the frequency and mean intensity of deep convection increase with SST from 26 to $30^{\circ} \mathrm{C}$. This explains why the bulk of tropical precipitation is observed in a narrow band slightly north of the Equator. However, the characteristics of the excited GWs varies (e.g., Salby and Garcia, 1987; Chun and Baik, 1998; Beres et al., 2004 ) with the altitude distribution of water vapor condensation and hence latent heat release in the clouds as well as with the temporal and spatial scales of the clouds. For instance, Kodama et al. (2009) showed that a large percentage of the rain in the ITCZ is stratiform rain. On the other hand, the relative importance of regions such as the western Indian Ocean or around Florida for the total distribution is far larger if only rain from deep convection is considered than they are in the distribution of total precipitation. The strong dominance of the ITCZ in total precipitation therefore is not necessarily reflected in GWMF. This is partly supported by the modeling work of Beres et al. (2005) (cf. their Fig. 1), which predicts larger heating depths and more significant heating amplitudes for the subtropical regions. Choi and Chun (2013) also demonstrated that the WFRF in the subtropics makes the cloud-top GWMF larger than that in the tropic regions where stronger diabatic heating exists.

Shorter vertical wavelengths could, in addition to wind modulation, explain why we observe very low values of GWMF along the ITCZ. Should the vertical wavelength (and horizontal phase speed) of the GWs excited in the ITCZ remain small, these waves would have low saturation amplitudes and hence not be very important in the stratosphere. However, it is also conceivable that the waves are important but difficult to observe. If the horizontal wavelength of the waves were to be smaller than $100 \mathrm{~km}$, they would be observed by a limb sounder only with a very fortunate observation geometry (cf. Preusse et al., 2002; Alexander et al., 2010). However, not only limb sounders miss finding a tropical GW maximum; satellite observations using nadir and sub-limb geometry also do not detect a pronounced GW maximum over the ITCZ. For example, low GW activity above the ITCZ is retrieved from techniques such as microwave sub-limb observations by MLS (McLandress et al., 2000; Jiang et al., 2004b) and nadir-viewing infrared observations by AIRS (Choi et al., 2012). Their absence in all space observations would therefore confine the wavelengths of GWs in the ITCZ, if present, to both short vertical and short horizontal scales (Preusse et al., 2008). In a modeling study, Choi et al. (2012) predicted that in the tropics, GWs could be difficult to observe. As there are free parameters in the global parameterizations of convective GW excitation, the predicted visibility of the waves is subject to tuning as well. 


\section{Appendix C: Construction of the artificial SST}

Technically, the artificial SST is constructed by first performing a regression to the function

$Y=A_{0}+B \cdot t+C \cdot \sin \left(\frac{2 \pi}{S} \cdot t+D\right)$,

where $Y$ is SST, $A_{0}$ is an offset, $B$ is the trend, $C$ is the amplitude of the oscillation, $D$ is the phase component, $S$ is the dominant frequency (in this case, 12 months) and $t$ is time. The variables $A_{0}, B, C$ and $D$ are determined via a leastsquares fit applied to SST data between 1981 and 2011. From this fit, we reconstruct an artificial SST $Y_{\mathrm{a}}$ by using only the sinusoid

$Y_{\mathrm{a}}=\sin \left(\frac{2 \pi}{S} \cdot t+D\right)$.

The artificial SST hence represents the amplitudenormalized annual cycle of the SST. In other words, this term represents a sinusoid of a 12-month period with an amplitude of 1 and minimizing/maximizing approximately at the same time when the SST minimizes/maximizes. Temporal variations shorter or longer than the annual cycle and the mean value and the trend are removed. The artificial SST data are constructed by calculating the sinusoid for all times in the investigated period (2002-2010) using an amplitude of $1{ }^{\circ} \mathrm{C}$ instead of the true amplitude. Figure A3 shows the phase of the annual cycle of SST in terms of the month in which the largest SST is reached. Outside the tropics, SST attains its maximum shortly after the solstice. Global maps for the individual months are constructed from the sinusoidal fits. As an example, the map for July is shown in Fig. A3b. Using an amplitude of $1{ }^{\circ} \mathrm{C}$, SST values vary between -1 and $1^{\circ} \mathrm{C}$. It should be noted that with the exception of a few signatures close to the Equator, overall features are dominated by largescale variations. 
Acknowledgements. The high quality of the SABER data is essential to this study and we thank the SABER team and in particular the PIs James M. Russell III and Martin Mlynczak for their efforts regarding the instrument and data retrieval. The NOAA optimum interpolation (OI) sea surface temperature (SST) version 2 monthly data and Global Precipitation Climatology Project (GPCP) version 2.1 precipitation monthly data are provided by the NOAA/OAR/ESRL Physical Sciences Division, Boulder, Colorado, USA, from their website at http://www.esrl.noaa.gov/psd/. J. Y. Jia was supported by the National Natural Science Foundation of China for young scientists (no. 41205064) and the Priority Academic Program Development of Jiangsu Higher Education Institutions (PAPD). H.-Y. Chun was supported by the Korean Meteorological Administration Research and Development Program under grant CATER_2012-3054. The authors highly appreciate the constructive comments of two anonymous reviewers which largely helped in improving the manuscript.

The service charges for this open access publication

have been covered by a Research Centre of the

Helmholtz Association.

Topical Editor C. Jacobi thanks two anonymous referees for their help in evaluating this paper.

\section{References}

Adler, R., Huffman, G., and Keehn, P.: Global rain estimates from microwave-adjusted geosynchronous IR data, Remote Sens. Rev., 11, 125-15, 1994.

Adler., R., Huffman, G., Chang, A., Ferraro, R., Xie, P., Janowiak, J., Rudolf, B., Schneider, U., Curtis, S., Bolvin, D., Gruber, A., Susskind, J., Arkin, P., and Nelkin, E.: The Version 2 Global Precipitation Climatology Project (GPCP) Monthly Precipitation Analysis (1979-Present), J. Hydrometeor., 4, 1147-1167, 2003.

Alexander, M. J. and Pfister, L.: Gravity wave momentum flux in the lower stratosphere over convection, Geophys. Res. Lett., 22, 2029-2032, doi:10.1029/95GL01984, 1995.

Alexander, M. J., Beres, J. H., and Pfister, L.: Tropical Stratospheric Gravity Wave Activity and Relationships to Clouds, J. Geophys. Res., 105, 22299-22309, doi:10.1029/2000JD900326, 2000.

Alexander, M. J., Geller, M., McLandress, C., Polavarapu, S., Preusse, P., Sassi, F., Sato, K., Eckermann, S., Ern, M., Hertzog, A., Kawatani, Y., Pulido, M., Shaw, T. A., Sigmond, M., Vincent, R., and Watanabe, S.: Recent developments in gravity-wave effects in climate models and the global distribution of gravitywave momentum flux from observations and models, Q. J. R. Meteorol. Soc., 136, 1103-1124, doi:10.1002/qj.637, 2010.

Arkin, P. and Meisner, B. N.: The relationship between large-scale convective rainfall and cold cloud over the Western Hemisphere during 1982-1984, Mon. Weather Rev., 115, 51-74, 1987.

Balmaseda, M. A., Trenberth, K. E., and Kallén, E.: Distinctive climate signals in reanalysis of global ocean heat content, Geophys. Res. Lett., 40, 1754-1759, 2013.

Beres, J. H., Alexander, M. J., and Holton, J. R.: A method of specifying the gravity wave spectrum above convection based on latent heating properties and background wind, J. Atmos. Sci., 61, 324-337, 2004
Beres, J. H., Garcia, R. R., Boville, B. A., and Sassi, F.: Implementation of a gravity wave source spectrum parameterization dependent on the properties of convection in the Whole Atmosphere Community Climate Model (WACCM), J. Geophys. Res., 110, D10108, doi:10.1029/2004JD005504, 2005.

Choi, E.-H. and Chun, H.-Y.: Generation mechanisms of convectively induced internal gravity waves in a threedimensional framework, Asia-Pac. J. Atmos. Sci., 50, 163-177, doi:10.1007/s13143-014-0005-x, 2014.

Choi, H.-J. and Chun, H.-Y.: Momentum Flux Spectrum of Convective Gravity Waves. Part I: An Update of a Parameterization Using Mesoscale Simulations, J. Atmos. Sci., 68, 739-759, doi:10.1175/2010JAS3552.1, 2011.

Choi, H.-J. and Chun, H.-Y.: Effects of convective gravity wave drag in the Southern Hemisphere winter stratosphere, J. Atmos. Sci., 70, 2120-2136, doi:10.1175/JAS-D-12-0238.1, 2013.

Choi, H.-J., Chun, H.-Y., and Song, I.-S.: Gravity wave temperature variance calculated using the ray-based spectral parameterization of convective gravity waves and its comparison with Microwave Limb Sounder observations, J. Geophys. Res., 114, D08111, doi:10.1029/2008JD011330, 2009.

Choi, H.-J., Chun, H.-Y., Gong, J., and Wu, D. L.: Comparison of gravity wave temperature variances from ray-based spectral parameterization of convective gravity wave drag with AIRS observations, J. Geophys. Res., 117, D05115, doi:10.1029/2011JD016900, 2012.

Chun, H.-Y. and Baik, J.-J.: momentum Flux by Thermally Induced Internal gravity Waves and Its Approximation for Large-Scale Models, J. Atmos. Sci., 55, 3299-3310, 1998.

Eckermann, S. D. and Marks, C. J.: GROGRAT: a New Model of the Global propagation and Dissipation of Atmospheric Gravity Waves, Adv. Space Res., 20, 1253-1256, 1997.

Eckermann, S. D. and Preusse, P.: Global measurements of stratospheric mountain waves from space, Science, 286, 1534-1537, 1999.

Emanuel, K.: Increasing destructiveness of tropical cyclones over the past 30 years, Nature, 436, 686-688, doi:10.1038/nature03906, 2005.

Ern, M. and Preusse, P.: Gravity wave momentum flux spectra observed from satellite in the summertime subtropics: Implications for global modeling, Geophys. Res. Lett., 39, L21801, doi:10.1029/2012GL052659, 2012.

Ern, M., Preusse, P., Alexander, M. J., and Warner, C. D.: Absolute values of gravity wave momentum flux derived from satellite data, J. Geophys. Res., 109, D20103, doi:10.1029/2004JD004752, 2004.

Ern, M., Preusse, P., and Warner, C. D.: Some experimental constraints for spectral parameters used in the Warner and McIntyre gravity wave parameterization scheme, Atmos. Chem. Phys., 6, 4361-4381, doi:10.5194/acp-6-4361-2006, 2006.

Ern, M., Preusse, P., Gille, J. C., Hepplewhite, C. L., Mlynczak, M. G., Russell III, J. M., and Riese, M.: Implications for atmospheric dynamics derived from global observations of gravity wave momentum flux in stratosphere and mesosphere, J. Geophys. Res., 116, D19107, doi:10.1029/2011JD015821, 2011.

Ern, M., Preusse, P., Kalisch, S., Kaufmann, M., and Riese, M.: Role of gravity waves in the forcing of quasi two-day waves in the mesosphere: An observational study, J. Geophys. Res. Atmos., 118, 3467-3485, doi:10.1029/2012JD018208, 2013. 
Ern, M., Ploeger, F., Preusse, P., Gille, J. C., Gray, L. J., Kalisch, S., Mlynczak, M. G., Russell III, J. M., and Riese, M.: Interaction of gravity waves with the QBO: A satellite perspective, J. Geophys. Res. Atmos., 119, 2329-2355, doi:10.1002/2013JD020731, 2014.

Fritts, D. and Alexander, M.: Gravity wave dynamics and effects in the middle atmosphere, Rev. Geophys., 41, 1003, doi:10.1029/2001RG000106, 2003.

Geller, M. A., Zhou, T., Ruedy, R., Aleinov, I., Nazarenko, L., Tausnev, N. L., Sun, S., Kelley, M., and Cheng, Y.: New Gravity Wave Treatments for GISS Climate Models, J. Climate, 24, 3989-4002, doi:10.1175/2011JCLI4013.1, 2011.

Geller, M. A., Alexander, M. J., Love, P. T., Bacmeister, J., Ern, M., Hertzog, A., Manzini, E., Preusse, P., Sato, K., Scaife, A. A., and Zhou, T.: A comparison between gravity wave momentum fluxes in observations and climate models, J. Climate, 26, 6383-6405, doi:10.1175/JCLI-D-12-00545.1, 2013.

Gille, J., Barnett, J., Arter, P., Barker, M., Bernath, P., Boone, C., Cavanaugh, C., Chow, J., Coffey, M., Craft, J., Craig, C., Dials, M., Dean, V., Eden, T., Edwards, D. P., Francis, G., Halvorson, C., Harvey, L., Hepplewhite, C., Khosravi, R., Kinnison, D., Krinsky, C., Lambert, A., Lee, H., Lyjak, L., Loh, J., Mankin, W., Massie, S., McInerney, J., Moorhouse, J., Nardi, B., Packman, D., Randall, C., Reburn, J., Rudolf, W., Schwartz, M., Serafin, J., Stone, K., Torpy, B., Walker, K., Waterfall, A., Watkins, R., Whitney, J., Woodard, D., and Young, G.: High Resolution Dynamics Limb Sounder: Experiment overview, recovery, and validation of initial temperature data, J. Geophys. Res. Atmos., 113, D16S43, doi:10.1029/2007JD008824, 2008.

Gille, J. C., Barnett, J. J., Whitney, J. G., Dials, M. A., Woodard, D., Rudolf, W. P., Lambert, A., and Mankin, W.: The HighResolution Dynamics Limb Sounder (HIRDLS) experiment on AURA, Proceedings of SPIE, 5152, 161-171, 2003.

Grody, N.: Classification of snow cover and precipitation using the Special Sensor Microwave/Imager (SSM/I), J. Geophys. Res., 96, 7423-7435, 1991.

Hirata, H. and Kawamura, R.: Scale interaction between typhoons and the North Pacific subtropical high and associated remote effects during the Baiu/Meiyu season, J. Geophys. Res. Atmos., 119, 5157-5170, doi:10.1002/2013JD021430, 2014.

Hoffmann, P., Becker, E., Singer, W., and Placke, M.: Seasonal variation of mesospheric waves at northern middle and high latitudes, J. Atmos. Sci., 72, 1068-1079, doi:10.1016/j.jastp.2010.07.002, 2010.

Hoyos, C., Agudelo, P., Webster, P., and Curry, J.: Deconvolution of the factors contributing to the increase in global hurricane intensity, Science, 312, 94-97, doi:10.1126/science.1123560, 2006.

Huffman, G., Adler, R., Bolvin, D., and Gu, G.: Improving the Global Precipitation Record: GPCP Version 2.1, Geophys. Res. Lett., 36, L17808, doi:10.1029/2009GL040000, 2009.

Ishikawa, Y., Awaji, T., and Akitomo, K.: Global Surface Circulation and Its Kinetic Energy Distribution Derived from Drifting Buoys, J. Oceanogr., 53, 489-516, 1997.

Jiang, J., Eckermann, S., Wu, D., and Ma, J.: A search for mountain waves in MLS stratospheric limb radiances from the winter Northern Hemisphere: Data analysis and global mountain wave modeling, J. Geophys. Res. Atmos., 109, doi:10.1029/2003JD003974, 2004a.
Jiang, J., Wang, B., Goya, K., Hocke, K., Eckermann, S., Ma, J., Wu, D., and Read, W.: Geographical distribution and interseasonal variability of tropical deep convection: UARS MLS observations and analyses, J. Geophys. Res. Atmos., 109, doi:10.1029/2003JD003756, 2004b.

Kalisch, S., Preusse, P., Ern, M., Eckermann, S. D., and Riese, M.: Differences in gravity wave drag between realistic oblique and assumed vertical propagation, J. Geophys. Res.-Atmos., 1008110099, doi:10.1002/2014JD021779, 2014.

Kim, S.-Y. and Chun, H.-Y.: Stratospheric gravity waves generated by Typhoon Saomai (2006): Numerical modeling in a moving frame following the typhoon, J. Atmos. Sci., 67, 3617-3636, 2010.

Kim, S.-Y., Chun, H.-Y., and Baik, J.-J.: A numerical study of gravity waves induced by convection associated with Typhoon Rusa, Geophys. Res. Lett., 32, L24816, doi:10.1029/2005GL024662, 2005.

Kim, S.-Y., Chun, H.-Y., and Wu, D. L.: A study on stratospheric gravity waves generated by typhoon Ewiniar: Numerical simulations and satellite observations, J. Geophys. Res., 114, D22104, doi:10.1029/2009JD011971, 2009.

Kim, Y.-J., Eckermann, S. D., and Chun, H.-Y.: An overview of the past, present and future of gravity-wave drag parameterization for numerical climate and weather prediction models, Atmos.Ocean, 41, 65-98, 2003.

Kirkwood, S., Mihalikova, M., Rao, T. N., and Satheesan, K.: Turbulence associated with mountain waves over Northern Scandinavia - a case study using the ESRAD VHF radar and the WRF mesoscale model, Atmos. Chem. Phys., 10, 3583-3599, doi:10.5194/acp-10-3583-2010, 2010.

Knapp, K. R., Kruk, M. C., Levinson, D. H., Diamond, H. J., and Neumann, C. J.: The international best track archive for climate stewardship (IBTRACS) unifying tropical cyclone data, Bull. Amer. Meteor. Soc., 91, 363-376, doi:10.1175/2009BAMS2755.1, 2010.

Kodama, Y.-M., Katsumata, M., Mori, S., Satoh, S., Hirose, Y., and Ueda, H.: Climatology of Warm Rain and Associated Latent Heating Derived from TRMM PR Observations, J. Clim.ate, 22, 4908-4929, doi:10.1175/2009JCLI2575.1, 2009.

Krebsbach, M. and Preusse, P.: Spectral analysis of gravity wave activity in SABER temperature data, Geophys. Res. Lett., 34, L03814, doi:10.1029/2006GL028040, 2007.

Manzini, E. and McFarlane, N. A.: The effect of varying the source spectrum of a gravity wave parameterization in a middle atmosphere general circulation model, J. Geophys. Res., 103, 3152331539, 1998.

Marks, C. J. and Eckermann, S. D.: A three-dimensional nonhydrostatic ray-tracing model for gravity waves: formulation and preliminary results for the middle atmosphere, J. Atmos. Sci., 52, 1959-1984, 1995.

McLandress, C., Alexander, M. J., and Wu, D. L.: Microwave Limb Sounder observations of gravity waves in the stratosphere: a climatology and interpretation, J. Geophys. Res., 105, 947-967, 2000.

Meenu, S., Parameswaran, K., and Rajeev, K.: Role of sea surface temperature and wind convergence in regulating convection over the tropical Indian Ocean, J. Geophys. Res., 117, D14102, doi:10.1029/2011JD016947, 2012. 
Mertens, C. J., Schmidlin, F. J., Goldberg, R. A., Remsberg, E. E., Pesnell, W. D., Russel III, J. M., Mlynczak, M. G., LopezPuertas, M., Wintersteiner, P. P., Picard, R. H., Winick, J. R., and Gordley, L. L.: SABER observations of mesospheric temperatures and comparisons with falling sphere measurements taken during the 2002 summer MaCWAVE campaign, Geophys. Res. Lett., 31, L03105, doi:10.1029/2003GL018605, 2004.

Mlynczak, M. G.: Energetics of the mesosphere and lower thermosphere and the SABER experiment, Adv. Space Res., 20, 11771183, 1997.

Oberheide, J., Hagan, M., Ward, W., Riese, M., and Offermann, D.: Modeling the diurnal tide for the Cryogenic Infrared Spectrometers and Telescopes for the Atmosphere (CRISTA) 1 time period, J. Geophys. Res., 105, 24917-24929, doi:10.1029/2000JA000047, 2000.

Pfister, L., Scott, S., Loewenstein, M., Brown, S., and Legg, M.: Mesoscale disturbances in the tropical stratosphere excited by convection: Observations and effects on the stratospheric momentum budget, J. Atmos. Sci., 50, 1058-1075, 1993.

Preusse, P.: Satellitenmessungen von Schwerewellen in der mittleren Atmosphäre mit CRISTA, Wuppertal University, 9, phD thesis, 2001

Preusse, P. and Ern, M.: Indication of convectively generated gravity waves observed by CLAES, Adv. Space Res., 35, 1987-1991, doi:10.1016/j.asr.2004.09.005, 2005.

Preusse, P., Eidmann, G., Eckermann, S. D., Schaeler, B., Spang, R., and Offermann, D.: Indications of convectively generated gravity waves in CRISTA temperatures, Adv. Space Res., 27, 16531658, 2001a.

Preusse, P., Eckermann, S., Oberheide, J., Hagan, M., and Offermann, D.: Modulation of gravity waves by tides as seen in CRISTA temperatures, Adv. Space Res., 27, 1773-1778, doi:10.1016/S0273-1177(01)00336-2, 2001b.

Preusse, P., Doernbrack, A. D., Eckermann, S. D., Riese, M., Schaeler, B., Bacmeister, J., Broutman, D., and Grossmann, K. U.: Space based measurements of stratospheric mountain waves by CRISTA, 1. Sensitivity, analysis method and a case study, J. Geophys. Res., 107, 8178, doi:10.1029/2001JD000699, 2002.

Preusse, P., Ern, M., Eckermann, S. D., Warner, C. D., Picard, R. H., Knieling, P., Krebsbach, M., Russel III, J. M., Mlynczak, M. G., Mertens, C. J., and Riese, M.: Tropopause to mesopause gravity waves in August: measurement and modeling, J. Atmos. SolarTerr. Phys., 68, 1730-1751, 2006.

Preusse, P., Eckermann, S. D., and Ern, M.: Transparency of the atmosphere to short horizontal wavelength gravity waves, J. Geophys. Res., 113, D24104, doi:10.1029/2007JD009682, 2008.

Preusse, P., Eckermann, S. D., Ern, M., Oberheide, J., Picard, R. H., Roble, R. G., Riese, M., Russell III, J. M., and Mlynczak, M. G.: Global ray tracing simulations of the SABER gravity wave climatology, J. Geophys. Res., 114, D08126, doi:10.1029/2008JD011214, 2009a.

Preusse, P., Schroeder, S., Hoffmann, L., Ern, M., Friedl-Vallon, F., Ungermann, J., Oelhaf, H., Fischer, H., and Riese, M.: New perspectives on gravity wave remote sensing by spaceborne infrared limb imaging, Atmos. Meas. Tech., 2, 299-311, doi:10.5194/amt-2-299-2009, 2009b.

Purkey, S. G. and Johnson, G. C.: Warming of Global Abyssal and Deep Southern Ocean Waters between the 1990s and 2000s:
Contributions to Global Heat and Sea Level Rise Budgets, J. Climate, 23, 6336-6351, doi:10.1175/2010JCLI3682.1, 2010.

Réchou, A., Arnault, J., Dalin, P., and Kirkwood, S.: Case study of stratospheric gravity waves of convective origin over Arctic Scandinavia - VHF radar observations and numerical modelling, Ann. Geophys., 31, 239-250, doi:10.5194/angeo-31-239-2013, 2013.

Remsberg, E. E., Marshall, B. T., Garcia-Comas, M., Krueger, D., Lingenfelser, G. S., Martin-Torres, J., Mlynczak, M. G., Russell III, J. M., Smith, A. K., Zhao, Y., Brown, C., Gordley, L. L., Lopez-Gonzalez, M. J., Lopez-Puertas, M., She, C. Y., Taylor, M. J., and Thompson, R. E.: Assessment of the quality of the Version 1.07 temperature-versus-pressure profiles of the middle atmosphere from TIMED/SABER, J. Geophys. Res., 113, D17101, doi:10.1029/2008JD010013, 2008.

Reynolds, R., Rayner, N., Smith, T., Stokes, D., and Wang, W.: An improved in situ and satellite SST analysis for climate, J. Clim., 15, 1609-1625, doi:10.1175/15200442(2002)015<1609:AIISAS>2.0.CO;2, 2002.

Ricciardulli, L. and Garcia, R. R.: The excitation of equatorial waves by deep convection in the NCAR Community Climate Model (CCM3), J. Atmos. Sci., 57, 3461-3487, 2000.

Richter, J. H., Sassi, F., and Garcia, R. R.: Toward a physically based gravity wave source parameterization in a general circulation model, J. Atmos. Sci., 67, 136-156, 2010.

Russell III, J. M., Mlynczak, M. G., Gordley, L. L., Tansock, J., and Esplin, R.: An overview of the SABER experiment and preliminary calibration results, Proceeding SPIE, 3756, 277-288, 1999.

Salby, M. L. and Garcia, R. R.: Transient response to localized episodic heating in the tropics. Part I: Excitation and short-time near-field behavior, J. Atmos. Sci., 44, 458-498, 1987.

Sato, K., Yamamori, M., Ogino, S. Y., Takahashi, N., Tomikawa, Y., and Yamanouchi, T.: A meridional scan of the stratospheric gravity wave field over the ocean in 2001 (MeSSO2001), J. Geophys. Res., 108, 4491, doi:10.1029/2002JD003219, 2003.

Sato, K., Watanabe, S., Kawatani, Y., Tomikawa, Y., Miyazaki, K., and Takahashi, M.: On the origins of mesospheric gravity waves, Geophys. Res. Lett., 36, doi:10.1029/2009GL039908, 2009.

Song, I. S. and Chun, H. Y.: Momentum flux spectrum of convectively forced internal gravity waves and its application to gravity wave drag parameterization. Part I: theory, J. Atmos. Sci., 62, 107-124, 2005.

Song, I.-S. and Chun, H.-Y.: A Lagrangian spectral parameterization of gravity wave drag induced by cumulus convection, J. Atmos. Sci., 65, 1204-1224, 2008.

Song, I.-S., Chun, H.-Y., Garcia, R. R., and Boville, B. A.: Momentum flux spectrum of convectively forced internal gravity waves and its application to gravity wave drag parameterization. Part II: Impacts in a GCM (WACCM), J. Atmos. Sci., 64, 2286-2308, 2007.

Spang, R., Eidmann, G., Riese, M., Offermann, D., Preusse, P., Pfister, L., and Wang, P.-H.: CRISTA observations of cirrus clouds around the tropopause, J. Geophys. Res., 107, 8174 doi:10.1029/2001JD000698, 2002.

Sud, Y., Walker, G. K., and Lau, K.-M.: Mechanisms regulating seasurface temperatures and deep convection in the tropics, Geophys. Res. Lett., 26, 1019-1022, doi:10.1029/1999GL900197, 1999. 
Wright, C. J. and Gille, J. C.: HIRDLS observations of gravity wave momentum fluxes over the monsoon regions, J. Geophys. Res., 116, D12103, doi:10.1029/2011JD015725, 2011.

Wu, D. L. and Eckermann, S. D.: Global gravity variances from Aura MLS: characteristics and interpretation, J. Atmos. Sci., 65, 3695-3718, 2008.
Zhang, C.: Large-scale variability of atmospheric deep convection in relation to sea surface temperature in the tropics, J. Climate, 6, 1898-1913, 1993. 